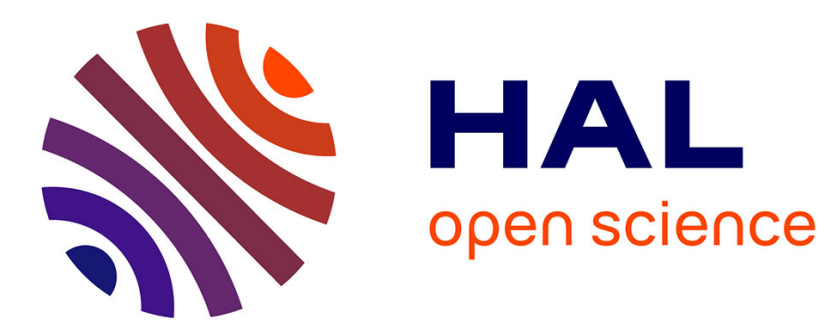

\title{
A person-centered perspective on the factors associated with the work recovery process
}

Nicolas Gillet, Alexandre J.S. Morin, René Mokounkolo, Christian Réveillère, Evelyne Fouquereau

\section{- To cite this version:}

Nicolas Gillet, Alexandre J.S. Morin, René Mokounkolo, Christian Réveillère, Evelyne Fouquereau. A person-centered perspective on the factors associated with the work recovery process. Anxiety, Stress and Coping, 2021, 34 (5), pp.571-596. 10.1080/10615806.2020.1866174 . hal-03145403

\author{
HAL Id: hal-03145403 \\ https://hal.science/hal-03145403
}

Submitted on 18 Feb 2021

HAL is a multi-disciplinary open access archive for the deposit and dissemination of scientific research documents, whether they are published or not. The documents may come from teaching and research institutions in France or abroad, or from public or private research centers.
L'archive ouverte pluridisciplinaire HAL, est destinée au dépôt et à la diffusion de documents scientifiques de niveau recherche, publiés ou non, émanant des établissements d'enseignement et de recherche français ou étrangers, des laboratoires publics ou privés. 
Running Head: Recovery Profiles

A Person-Centered Perspective on the Factors Associated with the Work Recovery Process

Nicolas Gillet*, Université de Tours, QualiPsy EE 1901, Tours, France

Institut Universitaire de France (IUF)

Alexandre J.S. Morin*, Substantive Methodological Synergy Research Laboratory, Department of Psychology, Concordia University, Montreal, Canada

René Mokounkolo, Université de Tours, QualiPsy EE 1901, Tours, France

Christian Réveillère, Université de Tours, QualiPsy EE 1901, Tours, France

Evelyne Fouquereau, Université de Tours, QualiPsy EE 1901, Tours, France

* The first two authors (N.G. \& A.J.S.M.) contributed equally to this article and their order was determined at random: Both should thus be considered first authors.

\title{
Corresponding author
}

Nicolas Gillet,

Université de Tours,

UFR Arts et Sciences Humaines,

Département de psychologie,

3 rue des Tanneurs, 37041 Tours Cedex 1, France

Phone : (+33) 2-47-36-65-54

E-mail: nicolas.gillet@univ-tours.fr

This is the prepublication version of the following manuscript:

Gillet, N., Morin, A. J. S., Mokounkolo, R., Réveillère, C., \& Fouquereau, E. (in press). A personcentered perspective on the factors associated with the work recovery process. Anxiety, Stress, \& Coping. Early view. https://doi.org/10.1080/10615806.2020.1866174

(C) 2020. This paper is not the copy of record and may not exactly replicate the authoritative document published in Anxiety, Stress, \& Coping.

\begin{abstract}
Background and Objectives: This research identified profiles characterized by distinct levels of overcommitment, rumination, psychological detachment (Studies 1 and 2), and need for recovery (Study 2). This research also considers the role of hindrance demands and resources in the prediction of profile membership, and the outcomes of these profiles.

Methods: These objectives were addressed in two empirical cross-sectional studies relying on selfreported questionnaires. Study 1 relies on a convenience sample of French workers from a variety of occupations. Study 2 relies on a convenience sample of French nurses and nursing assistants.

Results: Latent profile analyses revealed four identical profiles in both studies (High Ability to Achieve Recovery, Moderately High Ability to Achieve Recovery, Moderately Low Ability to Achieve Recovery, and Low Ability to Achieve Recovery), accompanied by an additional (Normative) profile in Study 2. The results from both studies revealed well-differentiated outcome associations, which generally matched the theoretical desirability of the identified profiles. Likewise, hindrance demands were associated with a decreased likelihood of membership into the High Ability to Achieve Recovery profile, as well as an increased likelihood of membership into the Low Ability to Achieve Recovery profile across studies.

Conclusions: Theoretical contributions and implications for practice are discussed.
\end{abstract}

Keywords: Work recovery, overcommitment, rumination, psychological detachment, need for recovery, social support at work, job demands, latent profile analysis. 


\section{Introduction}

Multiple psychological mechanisms are known to influence work recovery (Bennett et al., 2018), but have rarely been considered in combination. In this research, we focus on three of those critical psychological mechanisms: Psychological detachment, rumination, and overcommitment.

Psychological detachment involves the ability to stop thinking about work during off-job time and to be mentally involved in activities other than the job (Sonnentag \& Fritz, 2015). Indeed, the inability to stop thinking about work has the effect of maintaining employees' psychological systems in a state of activation, thus prohibiting recovery (Bennett et al., 2016). In contrast, psychological detachment helps to turn off these systems, thus helping psychological recovery from accumulated work-related energy expenditure (see Sonnentag \& Fritz, 2015, for a review). It is thus not surprising to note that psychological detachment has been found to be associated with lower levels of burnout and sleeping difficulties, and with higher levels of job satisfaction and performance (e.g., Kinnunen et al., 2017b).

Rumination refers to the opposite psychological mechanism whereby employees experience a continued state of preoccupation with work-related events (Demsky et al., 2019). More than just an inability to stop thinking about work, rumination involves a process via which employees, by forcefully trying to avoid negative work-related thoughts, come to experience these thoughts in a more acute manner, leading in turn to a variety of detrimental reactions interfering with recovery (Demsky et al., 2019). Rumination has been found to be associated with higher levels of burnout and sleeping difficulties, and with lower job satisfaction and work engagement (e.g., Kinnunen et al., 2017a).

Overcommitment is a generic orientation toward work that interferes with other components of the work recovery process (Potok \& Littman-Ovadia, 2014), defined as "a set of attitudes, behaviors and emotions that reflect excessive striving in combination with a strong desire of being approved and esteemed"' (Siegrist, 2001, p. 55). Research has revealed associations between overcommitment and a series of outcomes such as higher levels of burnout and sleeping difficulties, and lower levels of job satisfaction and performance (e.g., Feuerhahn et al., 2012; Huyghebaert et al., 2018).

In sum, although they have often been studied in an additive manner, the effects of these variables associated with the work recovery process has never been conceptualized as mutually exclusive or simply additive. Rather, these three psychological constructs are assumed to coexist and interact within employees (Kinnunen et al., 2017a, b; Sonnentag \& Fritz, 2015). However, prior research have explored psychological mechanisms likely to impact the recovery process as a composite of multiple variables (e.g., rumination and psychological detachment; van Wijhe et al., 2013), making it unclear which components were essential to achieve a complete understanding of the factors involved in work recovery. In addition, research in which separate factors were considered in their own right has typically focused on only one or two of these components (e.g., Sonnentag \& Bayer, 2005). In this regard, Sonnentag et al. (2017) noted that the bulk of prior research has largely focused on psychological detachment, thus overlooking the effects of other potentially critical factors equally likely to be involved in the work recovery process.

The simultaneous consideration of these various factors is likely to enrich our understanding of the work recovery process in many ways. For instance, which job demands and resources help (or hinder) employees achieve work recovery? Do workers need to display high levels of psychological detachment coupled with low levels of rumination and overcommitment to experience positive work outcomes? In contrast, are certain mechanisms (e.g., psychological detachment), but not others (e.g., rumination, overcommitment), more critical from an outcome perspective? As such, the present research represents a necessary step in understanding how employees jointly experience psychological detachment, rumination, and overcommitment in relation to job demands, job resources, and work outcomes.

This perspective seems to be naturally suited to the adoption of a person-centered approach to better understand the factors linked to employees' work recovery. Indeed, a person-centered perspective underscores the importance of studying the mechanisms related to the work recovery process in combination, rather than in isolation. More precisely, person-centered approaches are specifically designed to uncover the distinct configurations of mechanisms influencing the work recovery process that characterize distinct types, referred to as profiles, of employees.

\section{A Person-Centered Perspective on the Factors Involved in Work Recovery}

We were able to locate a total of eleven person-centered studies, published in ten different articles, which considered work recovery experiences or the factors associated with the recovery process (e.g., Bennett et al., 2016; Kinnunen et al., 2016, 2017a, b). The nature and characteristics of the profiles identified in these studies, as well as their associations with a variety of covariates, are summarized in 
Table S1 from the online supplements accompanying this article. As can be seen in this Table, the nature, number, and range of psychological constructs considered across these studies is quite large (psychological detachment, rumination, overcommitment, need for recovery, problem-solving pondering, work interruption in nonwork behaviors, relaxation, mastery, control, etc.). Furthermore, although most of these studies have been realized in Finland (thus limiting the generalizability of their findings), they have also relied on a great variety of samples (mixed employees samples, managers, school psychologists, etc.), methodological approaches (cross-sectional and longitudinal), and covariates of the work recovery process. This variety makes it particularly hard to achieve a clear integration of results. Importantly, none of these studies have considered the combined role of overcommitment, rumination, and psychological detachment in the formation of these distinct profiles of employees.

Yet, despite important variations across studies, the results seem to converge on profiles characterized by: (a) High Ability to Achieve Recovery (which would correspond, in the present research, to low levels of overcommitment and rumination, and high levels of psychological detachment); (b) Moderately High Ability to Achieve Recovery (corresponding to moderately low levels of overcommitment and rumination, and moderately high levels of psychological detachment); (c) Moderately Low Ability to Achieve Recovery (corresponding to moderately high levels of overcommitment and rumination, and moderately low levels of psychological detachment); and (d) Low Ability to Achieve Recovery (corresponding to high levels of overcommitment and rumination, and low levels of psychological detachment). This convergence of results from studies relying on different constructs measured differently is, in and of itself, highly informative in suggesting that the apparently different components linked to the work recovery process seem to capture a single overarching psychological mechanism (i.e., ability to achieve work recovery) when studied in combination. This overarching mechanism is illustrated by the fact that the emerging profiles only seem to differ quantitatively (workers presenting high, medium, or low levels across all dimensions) rather than qualitatively (workers presenting distinct patterns characterized by a mixture of high, medium, or low levels across dimensions) (Morin et al., 2016).

\section{Predictors of Employees' Profiles of Factors Involved in Work Recovery}

To achieve a complete understanding of the factors associated with the work recovery process, a next logical step is to identify what predicts membership in the profiles in order to guide interventions. Little research has considered predictors of recovery profiles. Among the few exceptions, Bennett et al. (2016) revealed associations between profile membership and exposure to various job demands and resources. Specifically, role ambiguity and time pressure were higher, and supervisor support for recovery was lower, in the profiles showing the least desirable recovery experiences than in more desirable profiles. Likewise, Kinnunen et al. (2017b) also found significant relations between job demands and employees' recovery profiles, showing that lower levels of time pressure, cognitive demands, and emotional demands tended to be associated with a greater likelihood of membership into the more desirable recovery profiles.

The present research expands on these previous results by focusing on a distinct set of job demands (emotional dissonance, workload, and bullying) and resources (perceived organizational, supervisor, and colleagues support) as possible predictors of profile membership. Given abundant evidence showing that demographic characteristics (i.e., sex, age, education, profession, work sector, work time, and tenure in the position) shared significant associations with both recovery processes and exposure to a variety of job demands and resources (e.g., Kinnunen et al., 2016), these associations were tested while taking into account the effects of these demographic characteristics.

According to the job demands-resources model (Bakker \& Demerouti, 2007), a health impairment process is activated by excessive demands that lead to physical and psychological health problems. Job demands refer to aspects of a job that require sustained physical and/or psychological effort and are associated with physiological and/or psychological costs (Meijman \& Mulder, 1998). These costs are likely to directly interfere with the work recovery process (Sonnentag \& Fritz, 2015). In contrast, job resources are aspects of the work environment that help enhance employees' well-being, support their performance, and reduce the costs associated with job demands (Bakker \& Demerouti, 2007). As such, job resources are likely to help enhance the work recovery process (Sonnentag \& Fritz, 2015).

The job demands considered in the present research (i.e., workload, emotional dissonance, and bullying) represent hindrance stressors (i.e., demands that unnecessarily obstruct personal growth and goal attainment) rather than challenge stressors (i.e., demands to be overcome to learn and achieve) (LePine et al., 2005). Hindrance stressors interfere with workers' self-actualization and need fulfillment (e.g., Albrecht, 2015). For this reason, they are likely to lead to a persistent activation of 
psychophysiological systems and persistent negative cognitive activation (Sonnentag \& Fritz, 2015) as a result of being unable to attain personal goals (e.g., Kinnunen et al., 2017b). This persistent activation is thus likely to interfere with the work recovery process (e.g., leading to more rumination, making it harder to psychologically detach; Sonnentag \& Bayer, 2005). Hindrance stressors could even increase overcommitment as employees' refuse to let go of their own personal needs when in the face of unreasonable demands (e.g., Huyghebaert et al., 2018). Hindrance demands may thus reinforce employees' tendencies to over-invest time and efforts at work, in turn inhibiting their ability to mentally switch off (Huyghebaert et al., 2018). Not surprisingly, the effects of hindrance demands are well documented in the prediction of a range of outcomes likely to emerge from the quality of the work recovery process, such as higher levels of emotional exhaustion and sleeping difficulties, and lower levels of job satisfaction and performance (e.g., Wirtz et al., 2017).

Finally, turning our attention to job resources, the work recovery research literature (Bennett et al., 2018; Sonnentag \& Fritz, 2015) explicitly assumes that social support from different sources (here the organization, supervisor, and colleagues) should directly contribute to more efficient work recovery. Indeed, job resources such as social support are likely to help employees face job demands more easily in order to achieve a greater level of need fulfillment at work (Bakker \& Demerouti, 2007). This greater feeling of fulfillment should make it easier for employees to let go (i.e., to psychologically detach and to avoid rumination) and less necessary for them to over-invest the work sphere (Gillet et al., 2017). Supporting these propositions, these three sources of social support have been repeatedly found to predict a variety of desirable outcomes assumed to result from the work recovery process, such as job satisfaction and performance (e.g., Gillet et al., 2013).

\section{Outcomes of Employees' Profiles of Factors Involved in Work Recovery}

As noted by Meyer and Morin (2016), it is critical to systematically assess the construct validity of person-centered solutions in order to ascertain that the extracted profiles of participants are meaningful in their own right. Although evidence of generalizability across studies, especially when integrating an additional component to the analysis, is an important first step in this direction, many scholars have underscored the critical importance of demonstrating that the identified profiles meaningfully relate to covariates (e.g., Marsh et al., 2009; Meyer \& Morin, 2016).

Consistent with theoretical predictions (Meijman \& Mulder 1998; Sonnentag \& Fritz, 2015), the previously reviewed person-centered studies (see Table S1 of the online supplements) have generally shown, despite some variations, that the High Ability to Achieve Recovery profile yielded the most positive work outcomes, followed by the Moderately High profile, then by the Moderately Low profile, and finally by the Low Ability to Achieve Recovery profile. These results are interesting as they seem to generalize to a wide range of work outcomes (e.g., sleeping difficulties, burnout, job satisfaction, performance, absenteeism, counter-productive behaviors).

\section{Study 1}

The present study seeks to document the characteristics of the profiles that best characterize the multidimensional factors (overcommitment, rumination, and psychological detachment) involved in employees' work recovery. This first study also investigates the role of emotional dissonance and workload (job demands) as well as organizational, supervisor, and colleagues support (job resources) as predictors of profile membership. We focus on the effects of these two types of job demands and resources because these characteristics have a known influence on the work recovery process (e.g., Gillet et al., 2020). To ascertain the construct validity of these profiles (Meyer \& Morin, 2016), we build on previous studies (e.g., Bennett et al., 2016) by considering outcomes reflecting employees' recovery success and difficulties (burnout, sleeping difficulties, and job satisfaction) but also documenting the work-related impact of this recovery process (job performance, absenteeism, and counter-productive work behaviors). These outcomes were retained based on previous results supporting their association with employees' work recovery processes (for a review, see Sonnentag \& Fritz, 2015).

Given the consistency of results obtained in previous studies, it seems reasonable to hypothesize:

Hypothesis 1. At least four profiles reflecting employees' recovery will be identified corresponding to High Ability to Achieve Recovery, Moderately High Ability to Achieve Recovery, Moderately Low Ability to Achieve Recovery, and Low Ability to Achieve Recovery configurations.

Hypothesis 2. The High Ability to Achieve Recovery profile will report the highest job satisfaction and performance, and the lowest burnout, sleeping difficulties, counter-productive behaviors, and absenteeism.

Hypothesis 3. The Low Ability to Achieve Recovery profile will report the lowest job satisfaction and 
performance, and the highest burnout, sleeping difficulties, counter-productive behaviors, and absenteeism.

Hypothesis 4. Higher workload and emotional dissonance will be associated with a greater likelihood of membership into the Low Ability to Achieve Recovery profile.

Hypothesis 5. Higher levels of perceived organizational support, supervisor support, and colleagues support will be associated with a greater likelihood of membership into the High Ability to Achieve Recovery profile.

Method

Participants and Procedure

A convenience sample of 415 workers (70 men; 345 women) from various organizations (e.g., public hospitals, industries, sales and services) located in France completed a paper-and-pencil questionnaire. In each organization, participants received a survey packet including the questionnaire, a cover letter explaining the study's purposes, and a written consent form stressing that participation was anonymous and voluntary. Questionnaires required approximately 20 minutes to complete. Completed questionnaires were returned to a member of the research team present on the day of data collection. No incentive was offered to take part in the study. This study follows the principles of the Declaration of Helsinki. The current sample included 167 participants employed in the public sector (40.2\%) and 247 employed in the private sector (59.5\%; one participant did not answer). Respondents were aged between 19 and 64 years $(M=37.90, S D=11.80)$, had an average organizational tenure of 10.40 years $(S D=10.26)$, and an average tenure in the current position of 6.38 years $(S D=6.96)$. A total of 320 participants worked full-time (77.1\%), 344 participants held permanent positions $(82.9 \%)$, and 71 were temporary workers $(17.1 \%)$. Seven participants $(1.7 \%)$ had no diploma, 63 had a vocational training certificate (15.2\%), 85 had a high school diploma $(20.5 \%)$, and 260 had a university diploma $(62.7 \%)$.

Measures

Psychological Detachment (Profile Indicator). Psychological detachment was assessed with a scale developed by Sonnentag and Fritz (2007). Following a common stem (i.e., "In the evening, after work, and when I am on a weekend/vacation..."), four items ( $\alpha=.88$; e.g., "I forget about work") were rated on a five-point scale ranging from 1 (totally disagree) to 5 (totally agree).

Overcommitment (Profile Indicator). We used the six items (e.g., "I get easily overwhelmed by time pressures at work."; $\alpha=.82$ ) from the Effort-Reward Imbalance Questionnaire (Siegrist, 1996) to assess overcommitment. Ratings were provided on a five-point scale (1-disagree to 5-agree).

Rumination (Profile Indicator). Rumination was assessed using two items ("I worry about things that have to be done at work" and "I ruminate about things that have happened at work"; $\alpha=.71$ ) developed and validated by de Bloom et al. (2014). Following a stem ("In the evening, after work, and when I am on a weekend/vacation..."), ratings were provided on a five-point scale ( 1 = strongly disagree, $5=$ strongly agree) .

Emotional Dissonance (Predictor). Emotional dissonance was assessed with five items $(\alpha=.84$; e.g., "Having to show certain feelings that do not correspond with the way I feel at that moment") from the Frankfurt Emotion Work Scale (Zapf et al., 1999) rated on a five-point scale ranging from 1 (never) to 5 (always).

Workload (Predictor). Spector and Jex's (1998) five-item Quantitative Workload Inventory was used to measure workload (e.g., "How often does your job require you to work very hard?"; $\alpha=.85$ ). Responses were provided on a five-point scale ranging from 1 (never) to 5 (always).

Perceived Organizational, Supervisor, and Colleagues Support (Predictor). Perceived organizational support was assessed using the short four-item version (Caesens et al., 2014) of Eisenberger et al.'s (1986) Survey of Perceived Organizational Support $(\alpha=.80$; e.g., "My organization really cares about my well-being"). Following Caesens et al. (2014), the same four items were used to assess perceived supervisor $(\alpha=.84$; e.g., "My supervisor cares about my general satisfaction at work") and colleagues ( $\alpha=.80$; e.g., "My colleagues really care about my well-being") support by replacing the word "organization" with the term "supervisor" or "colleagues". All of these items were rated on a seven-point scale ranging from "Strongly Disagree" to "Strongly Agree".

Counterproductive Work Behaviors (Outcome). Five items focusing on social interactions ( $\alpha=$ .59; e.g., "Insulted someone about their job performance") (Spector et al., 2010) were used to assess counterproductive work behaviors. Responses were provided on a five-point scale ranging from 1 (never) to 5 (every day). 
Absenteeism (Outcome). We relied on a single-item measure (Kessler et al., 2003) asking workers to report the number of entire work days missed during the last year because of problems related to their physical or mental health.

Emotional exhaustion (Outcome). Emotional exhaustion was assessed with the five-item subscale ( $\alpha=.86$; e.g., "I feel emotionally drained by my work") from the Maslach Burnout Inventory-General Survey (Schaufeli et al., 1996). All items were rated on a 1 (strongly disagree) to 5 (strongly agree) response scale.

Sleeping difficulties (Outcome). Four items $(\alpha=.88)$ developed by Jenkins et al. (1988) were used to measure sleeping difficulties over the past four weeks. Each item (i.e., "difficulty falling asleep", "difficulty staying asleep", "waking up several times per night", and "waking up feeling tired and worn out after the usual amount of sleep") was rated on a six-point scale: Not at all (1), 1 to 3 days (2), 4 to 7 days (3), 8 to 14 days (4), 15 to 21 days (5), and 22 to 28 days (6).

Job satisfaction (Outcome). Job satisfaction was assessed with a one-item measure (Shimazu et al., 2015; i.e., "Are you satisfied with your job?"). Responses were indicated on a scale ranging from 1 (dissatisfied) to 4 (satisfied).

Job performance (Outcome). Work performance was assessed with a one-item measure ("How would you rate your overall job performance on the days you worked during the past four weeks") from the World Health Organization Health and Work Performance Questionnaire (Kessler et al., 2003) and rated on a scale from 0 (worst performance) to 10 (best performance).

\section{Analyses}

Preliminary Analyses

The psychometric properties of all multi-item measures were verified via preliminary factor analyses. Factor scores were saved from these measurement models in standardized units (with $M=0$, $S D=1$ in the total sample) for the main analyses (Meyer \& Morin, 2016). Factor scores provide a partial control by giving more weight to more reliable items and preserve the underlying nature of the measurement model (e.g., Morin et al., 2016). Details on these models, tests of differentiability among profile indicators, and estimates of composite reliability are reported in the online supplements. Correlations among all variables are reported in these online supplements in Table S9.

Main Analyses

All of our main analyses were conducted using Mplus 8 (Muthén \& Muthén, 2017) robust maximum likelihood estimator (MLR), in conjunction with Full Information Maximum Likelihood (FIML; Enders, 2010) procedures to handle the limited amount of missing data present in this study (i.e., 0 to $1.0 \%$ ). To avoid converging on a local maximum, latent profile analyses (LPA) were estimated with 5000 random start values, allowed 1000 iterations each, and retaining the 200 best solutions for final optimization (Hipp \& Bauer, 2006). LPA including 1 to 8 profiles, in which the means and variances of the factors were freely estimated across profiles (Peugh \& Fan, 2013), were estimated using the overcommitment, psychological detachment, and rumination factor scores as profile indicators.

To determine the optimal number of profiles, multiple sources of information were considered, including the substantive meaningfulness, theoretical conformity, and statistical adequacy of the solutions (Morin \& Litalien, 2019). Statistical indices are available to support this decision: The Akaïke Information Criterion (AIC), the Consistent AIC (CAIC), the Bayesian Information Criterion (BIC), the sample-size Adjusted BIC (ABIC), the adjusted Lo et al.'s (2001) Likelihood Ratio Test (aLMR), and the Bootstrap Likelihood Ratio Test (BLRT). Lower AIC, CAIC, BIC, and ABIC values suggest a better-fitting model. Statistically significant aLMR and BLRT support the estimated model relative to a model including one less profile.

Simulation studies indicate that four indicators (CAIC, BIC, ABIC, and BLRT) are effective, while the others (AIC and LMR/ALMR) should not be used (e.g., Diallo et al., 2017; Peugh \& Fan, 2013). Thus, all indicators will be reported to ensure a complete disclosure, but not to select the optimal number of profiles. A recent study (Diallo et al., 2017) suggests that the BIC and CAIC should be privileged under conditions of high entropy $(\geq .800)$, whereas the ABIC and BLRT perform better in conditions of low entropy $(\leq .600)$. Because all of these indicators are sample size dependent (Marsh et al., 2009), they often suggest adding profiles without reaching a minimum. In this situation, the point at which these indicators reach a plateau suggests the optimal solution (Morin et al., 2016).

Multinomial logistic regressions were used to test the relations between the predictors, directly included into the final retained solution (Diallo et al., 2017), and the likelihood of profile membership. 
The profiles were also contrasted on various outcomes using a weighted multiple group mean comparison procedure (Bakk et al., 2013) implemented in Mplus through the Auxiliary (BCH) function (Asparouhov \& Muthén, 2015; for additional details on the advantage of this procedure, see Morin \& Litalien, 2019). Predictors and outcomes were incorporated to the model as factor scores saved from a preliminary measurement model.

\section{Results}

\section{Latent Profile Solutions}

The fit indices associated with LPA solutions including 1 to 8 profiles are reported in Table 1, and graphically presented in Figure S1 of the online supplements. The results first reveal a relatively high entropy (.808 to .911 across the eight models), indicating a relatively high level of classification accuracy. This observation suggests that the BIC and CAIC should be favored (Diallo et al., 2017). These two indices reach their lowest point for the 6-profile solution. In contrast, the ABIC and BLRT fail to converge on any specific solution. However, examination of Figure S1 (online supplements) suggests a flattening out in the decrease in the value of the information criteria located around 4 profiles. We thus carefully examined the 3-, 4-, 5-, and 6-profile solutions. This examination revealed that adding profiles resulted in the addition of meaningfully distinct configurations up to the 4-profile solution. After this, adding profiles simply resulted in the arbitrary division of already identified profiles into smaller ones (corresponding to less than $1 \%$ of the sample) presenting a similar shape. For this reason, the 4-profile solution was retained. This solution is graphically illustrated in Figure 1. Detailed parameter estimates from the 4-profile solution are reported in Table S11 of the online supplements. The results revealed a high level of classification accuracy of participants into their most likely profile, ranging from $91.8 \%$ to $95.9 \%$ (see Table S12 of the online supplements).

Members of Profile 1 were characterized by moderately low levels of overcommitment and rumination, and by moderately high levels of psychological detachment. This Moderately High Ability to Achieve Recovery profile characterized $44.66 \%$ of the employees. In contrast, members of Profile 2 were characterized by high overcommitment and rumination, and low psychological detachment. This Low Ability to Achieve Recovery profile characterized $12.75 \%$ of the employees. Members of Profile 3 were characterized by moderately high overcommitment and rumination, and moderately low psychological detachment. This Moderately Low Ability to Achieve Recovery profile characterized $31.13 \%$ of the employees. Finally, members of Profile 4 were characterized by low overcommitment and rumination, and by high psychological detachment. This High Ability to Achieve Recovery profile characterized $11.46 \%$ of the employees.

\section{Predictors of Profile Membership}

Associations between the various profiles and the predictors considered in the present study are reported in Table 2. Perceived organizational support, perceived supervisor support, perceived colleagues support, age, education, and work time were unrelated to the likelihood of membership into any of the profiles. Females were more likely than males to be members of the Low Ability to Achieve Recovery (2) profile relative to the High Ability to Achieve Recovery (4) profile. Public sector employees were less likely than private sector employees to be members of the Moderately Low Ability to Achieve Recovery (3) profile relative to the High Ability to Achieve Recovery (4) profile. In contrast, public sector employees were more likely than private sector employees to be members of the Moderately High Ability to Achieve Recovery (1) profile relative to the Moderately Low Ability to Achieve Recovery (3) profile. Tenure in the position was associated with a decrease likelihood of membership in the Moderately High Ability to Achieve Recovery (1), Low Ability to Achieve Recovery (2), and Moderately Low Ability to Achieve Recovery (3) profiles than in the High Ability to Achieve Recovery (4) profile. In addition, workload was associated with an increased likelihood of membership into the Moderately High Ability to Achieve Recovery (1), Low Ability to Achieve Recovery (2), and Moderately Low Ability to Achieve Recovery (3) profiles relative to the High Ability to Achieve Recovery (4) profile. Workload was also associated with an increased likelihood of membership into the Low Ability to Achieve Recovery (2) profile relative to the Moderately High Ability to Achieve Recovery (1) and Moderately Low Ability to Achieve Recovery (3) profiles. Emotional dissonance was associated with an increased likelihood of membership into the Low Ability to Achieve Recovery (2) and Moderately Low Ability to Achieve Recovery (3) profiles relative to the High Ability to Achieve Recovery (4) profile. Finally, emotional dissonance was associated with an increased likelihood of membership into the Low Ability to Achieve Recovery (2) profile relative to the Moderately High 
Ability to Achieve Recovery (1) profile.

Outcomes of Profile Membership

Associations between the various profiles and the outcomes considered in the present study are reported in Table 4. The four profiles could not be differentiated from one another in regard to counterproductive work behaviors and absenteeism. The highest levels of burnout and sleeping difficulties were associated with the Low Ability to Achieve Recovery (2) profile, followed by the Moderately Low Ability to Achieve Recovery (3) profile, by the Moderately High Ability to Achieve Recovery (1) profile, and finally by the High Ability to Achieve Recovery (4) profile (although these last two profiles could not be differentiated in terms of sleeping difficulties). The High Ability to Achieve Recovery (4) profile was associated with higher levels of job satisfaction than the Moderately Low Ability to Achieve Recovery (3) profile, which was itself associated with higher levels of job satisfaction than the Low Ability to Achieve Recovery (2) profile. In addition, the Moderately High Ability to Achieve Recovery (1) profile was associated with higher levels of job satisfaction than the Low Ability to Achieve Recovery (2) profile. The High Ability to Achieve Recovery (4) profile was associated with higher levels of job performance than the Moderately Low Ability to Achieve Recovery (3) and Moderately High Ability to Achieve Recovery (1) profiles, while this last profile was associated with higher levels of job performance than the Low Ability to Achieve Recovery (2) one.

\section{Brief Discussion}

Our results revealed four profiles presenting clear qualitative differences: Moderately High Ability to Achieve Recovery, Low Ability to Achieve Recovery, Moderately Low Ability to Achieve Recovery, and High Ability to Achieve Recovery. These results match previous studies (e.g., Bennett et al., 2016) and support Hypothesis 1. When these four profiles were considered from an outcomes' perspective, the Low Ability to Achieve Recovery profile was associated with the highest levels of burnout and the lowest levels of job satisfaction. In contrast, the High Ability to Achieve Recovery profile was associated with the lowest levels of burnout and sleeping difficulties, and the highest levels of job performance. These results generally support Hypotheses 2 and 3 and confirm that the ability to achieve recovery is associated with more positive outcomes (Sonnentag \& Fritz, 2007, 2015).

In addition, and in accordance with Hypothesis 4 and prior studies (e.g., Bennett et al., 2016), workload was associated with a higher likelihood of membership into the Low Ability to Achieve Recovery profile relative to the Moderately High Ability to Achieve Recovery and Moderately Low Ability to Achieve Recovery profiles. Emotional dissonance was also associated with a higher likelihood of membership into the Low Ability to Achieve Recovery and Moderately Low Ability to Achieve Recovery profiles relative to the High Ability to Achieve Recovery profile. Finally, emotional dissonance was associated with a higher likelihood of membership into the Low Ability to Achieve Recovery profile relative to the Moderately High Ability to Achieve Recovery profile. These results are aligned with the job demands-resources model (Bakker \& Demerouti, 2007).

Surprisingly, Hypothesis 5 was not supported as perceived organizational support, perceived supervisor support, perceived colleagues support were unrelated to the likelihood of membership into any of the profiles. These unexpected findings will be more extensively discussed in the general discussion and encouraged us to empirically verify the extent to which these results would generalize to a new sample of employees using a more comprehensive set of profile indicators (overcommitment, rumination, psychological detachment, and need for recovery). More generally, person-centered evidence is cumulative and formed by evidence obtained across a range of distinct samples and studies relying on a distinct set of profile indicators in order to differentiate the core subset of profiles that systematically emerge, the peripheral profiles that only emerge in specific situations, and the even less frequent set of profiles that simply reflect random sampling variations (e.g., Meyer \& Morin, 2016).

\section{Study 2}

As in Study 1, Study 2 examines how rumination, psychological detachment, and overcommitment combine within different subgroups of workers. In addition, the need for recovery, reflecting a desire to be temporarily relieved of ones' job demands in order to replenish resources (Sluiter et al., 1999), was considered as a fourth psychological mechanism in the definition of the profiles. The need for recovery is characterized by feelings of being overloaded at work and the lack of required energy to face this overload (van Veldhoven \& Broersen, 2003). As such, a high need for recovery reflects the extent to which employees feel that their resources are depleted, and this lack of resources in turn makes it harder for them to invest time and efforts in additional activities which may help them to recover (ten 
Brummelhuis \& Bakker, 2012). Research has supported associations between need for recovery and higher levels of sleeping difficulties, burnout, and absenteeism, and lower levels of life satisfaction and performance (e.g., Sluiter et al., 1999; Xanthopoulou et al., 2018).

Prior studies have shown that the need for recovery is intimately related to the three other dimensions. Research has typically considered the need for recovery to be an outcome of the other three, with the expectation that overcommitment and rumination would increase the need for recovery, whereas detachment will decrease it (Sonnentag \& Fritz, 2015). Yet, the need for recovery is, in and of itself, also likely to play a key role in influencing employees' ability to successfully recover from work, especially when considered in combination with the other components (Rydstedt et al., 2009). For instance, whereas overcommitment and rumination make it harder to recover from work, this might be less problematic for employees with a low need for recovery, just like psychological detachment could be particularly helpful for those with as acute need for recovery (Rivkin et al., 2015).

Past variable-centered studies are also unable to explain why some employees continue to think about work after hours (high levels of rumination) when their resources are low (high need for recovery), whereas other employees with sufficient resources (low need for recovery) still prefer to disengage from work as soon as possible when they get home (high psychological detachment) (Bennett et al., 2016). Considering that the need for recovery has often been taken to be a natural outcome of the other three mechanisms, it seemed like a strong candidate variable to incorporate to the definition of the profiles in order to assess the extent to which their nature would remained unchanged or transformed via the consideration of additional components. Given the observed stability of results observed in previous research relying on various indicators of work recovery, and the known associations between the need for recovery and the other components considered here, we do expect a substantial level of stability. Observing stability would also support the idea that the identified profiles tap into some core processes that remain unchanged irrespective of the specific psychological mechanisms that are considered. Yet, despite expecting stability, we leave as an open research question whether this additional inclusion could result in the estimation of distinct profiles, in accordance with the possibility that the intensity of the need for recovery could somehow differ across employees irrespective of their levels of psychological detachment, rumination, and overcommitment.

As in Study 1, this study considers the role of job demands (bullying) and resources (perceived organizational, supervisor, and colleagues support) in the prediction of workers' likelihood of membership into the profiles. In this study, the decision was made to replace workload, known to be systematically elevated for most nurses (Iordache et al., 2020), as a job demand indicator. Bullying was retained based on previous results supporting its importance in the nursing profession (Johnson, 2009) and association with recovery (Rodríguez-Muñoz et al., 2017). In line with Study 1 and prior research (e.g., Huyghebaert et al., 2018), we hypothesized that bullying will be associated with a greater likelihood of membership into the Low Ability to Achieve Recovery profile. However, given the inconsistent findings between Study 1 and prior research (e.g., Bennett et al., 2016), we leave as an open research question whether perceived organizational support, supervisor support, and colleagues support would relate to profile membership.

Finally, to better document the construct validity and practical relevance of the identified profiles, we assess how they relate to a variety of outcomes including, as in Study 1, burnout, sleeping difficulties, job satisfaction, and job performance. Given that counter-productive work behaviors and absenteeism were not significantly related to profile membership in Study 1, these outcomes were not considered in the present study. As in Study 1, we hypothesized that the High Ability to Achieve Recovery profile will report the highest job satisfaction and performance, and the lowest burnout and sleeping difficulties. In contrast, the Low Ability to Achieve Recovery profile will report the lowest job satisfaction and performance, and the highest burnout and sleeping difficulties.

\section{Method}

\section{Participants and Procedure}

This convenience sample included 302 nurses and 113 nursing assistants (23 men; 392 women) working in various hospitals located in France. These participants completed a paper-and-pencil questionnaire following the same procedures used in Study 1. This sample included 290 participants employed in the public sector (69.9\%) and 125 employed in the private sector $(30.1 \%)$. Respondents were aged between 18 and 60 years $(M=32.44, S D=9.48)$, had an average organizational tenure of 
6.23 years $(S D=6.65)$, and an average tenure in the current position of 4.40 years $(S D=4.95)$. A total of 365 participants worked full-time (88.0\%), 342 participants held permanent positions $(82.4 \%)$, and 50 were temporary workers $(12.0 \%)$.

\section{Measures}

The same questionnaires as in Study 1 were used to assess psychological detachment $(\alpha=.86)$, overcommitment $(\alpha=.79)$, rumination $(\alpha=.71)$, perceived organizational $(\alpha=.58)$, supervisor $(\alpha=$ $.82)$, and colleagues support $(\alpha=.80)$, emotional exhaustion $(\alpha=.86)$, sleeping difficulties $(\alpha=.85)$, job satisfaction, and job performance.

Need for Recovery. Using the four items from the short form (Xanthopoulou et al., 2018) of van Veldhoven and Broersen's (2003) need for recovery scale, participants indicated on a four-point scale ranging from 1 (never) to 4 (always) how often they experienced the described feelings (e.g., "Often, after a day's work I feel so tired that I cannot get involved in other activities"; $\alpha=.78$ ).

Bullying. Bullying was assessed with the Negative Acts Questionnaire-Revised (NAQ-R; Einarsen et al., 2009). This measure includes three types of negative acts: Person-related bullying (12 items; $\alpha=$ .91; e.g., "Being humiliated or ridiculed in connection with your work"), work-related bullying (7 items; $\alpha=.81$; e.g., "Someone withholding information which affects your performance"), and physically-intimidating bullying ( 3 items; $\alpha=.64$; e.g., "Being shouted at or being the target of spontaneous anger"). For each of the 22 items, respondents indicated how often they had been exposed to the behavior in question during the last six months on a five-point scale (1-never to 5-daily).

\section{Analyses}

Preliminary Analyses

As in Study 1, the psychometric properties of all multi-item measures were verified via factor analyses. Details on these models, tests of differentiability among profile indicators, tests of measurement invariance across samples for the subset of measures used in both studies, and estimates of composite reliability are reported in the online supplements. Correlations among all variables are reported in the online supplements in Table S10.

Main Analyses

LPA including 1 to 8 profiles, in which the means and variances of the factors were freely estimated across profiles (Peugh \& Fan, 2013), were estimated using the overcommitment, psychological detachment, rumination, and need for recovery factor scores. As in Study 1, multinomial logistic regressions were used to test the relations between the predictors, directly included into the final retained solution (Diallo et al., 2017), and the likelihood of profile membership. The profiles were also contrasted on various outcomes using a weighted multiple group mean comparison procedure (Bakk et al., 2013) implemented in Mplus through the Auxiliary (BCH) function (Asparouhov \& Muthén, 2015). Predictors and outcomes were incorporated to the model as factor scores saved from a preliminary measurement model.

\section{Results}

\section{Latent Profile Solutions}

The fit indices associated with the LPA solutions including 1 to 8 profiles are reported in Table 1 and graphically presented in Figure S2 of the online supplements. Examination of Figure S2 suggests a flattening out in the decrease in the value of the information criteria located around 3 to 5 profiles. We thus carefully examined the 3-, 4-, 5-, 6-, and 7-profile solutions. This examination revealed that adding profiles resulted in the addition of meaningfully distinct configurations up to the 5-profile solution. After this, adding profiles simply resulted in the arbitrary division of already identified profiles into smaller ones (corresponding to less than $1 \%$ of the sample) presenting a similar shape. For this reason, the 5-profile solution was retained (see Figure 2 and Table S13 of the online supplements). The results revealed a high level of classification accuracy of participants into their most likely profile, ranging from $90.0 \%$ to $94.4 \%$ (see Table S12 of the online supplements).

Members of Profile 1 were characterized by moderately low levels of overcommitment, rumination, and need for recovery, and by moderately high levels of psychological detachment. This Moderately High Ability to Achieve Recovery profile characterized $27.08 \%$ of the employees. Members of Profile 2 were characterized by low levels of overcommitment, rumination, and need for recovery, and by high levels of psychological detachment. This High Ability to Achieve Recovery profile characterized $7.34 \%$ of the employees. Members of Profile 3 were characterized by moderately high levels of overcommitment, rumination, and need for recovery, and by moderately low levels of 
psychological detachment. This Moderately Low Ability to Achieve Recovery profile characterized $21.43 \%$ of the employees. Members of Profile 4 presented average levels of overcommitment, rumination, need for recovery, and psychological detachment. This Normative profile characterized $35.47 \%$ of the employees. Finally, members of Profile 5 were characterized by high levels of overcommitment, rumination, and need for recovery, and by low levels of psychological detachment. This Low Ability to Achieve Recovery profile characterized $8.69 \%$ of the employees.

Predictors of Profile Membership

Associations between the various profiles and the predictors considered in the present study are reported in Table 3. Specific levels of person-related bullying, specific levels of physicallyintimidating bullying, perceived organizational support, perceived supervisor support, perceived colleagues support, sex, age, profession, and work time were all unrelated to the likelihood of membership into any of the profiles. Public sector employees were less likely than private sector employees to be members of the Moderately High Ability to Achieve Recovery (1), Moderately Low Ability to Achieve Recovery (3), and Normative (4) profiles relative to the Low Ability to Achieve Recovery (5) profile. Tenure in the position was associated with a higher likelihood of membership in the Moderately High Ability to Achieve Recovery (1), High Ability to Achieve Recovery (2), and Normative (4) profiles than in the Low Ability to Achieve Recovery (5) profile. Specific levels of workrelated bullying were associated with a decreased likelihood of membership into the Moderately High Ability to Achieve Recovery (1), High Ability to Achieve Recovery (2), and Normative (4) profiles relative to the Low Ability to Achieve Recovery (5) profile. They were also associated with a decreased likelihood of membership into the Moderately High Ability to Achieve Recovery (1) and High Ability to Achieve Recovery (2) profiles relative to the Normative (4) profile, as well as into the Moderately High Ability to Achieve Recovery (1) and High Ability to Achieve Recovery (2) profiles relative to the Moderately Low Ability to Achieve Recovery (3) profile. In addition, these specific levels of workrelated bullying were also associated with an increased likelihood of membership into the Moderately High Ability to Achieve Recovery (1) profile relative to the High Ability to Achieve Recovery (2) profile. Finally, global levels of bullying were associated with a decreased likelihood of membership into the Moderately High Ability to Achieve Recovery (1) and High Ability to Achieve Recovery (2) profiles relative to the Low Ability to Achieve Recovery (5) profile, as well as into the Moderately High Ability to Achieve Recovery (1) and High Ability to Achieve Recovery (2) profiles relative to the Moderately Low Ability to Achieve Recovery (3) profile. Finally, these global levels of bullying were also associated with a decreased likelihood of membership into the Moderately High Ability to Achieve Recovery (1) and High Ability to Achieve Recovery (2) profiles relative to the Normative (4) profile, as well as an increased likelihood of membership into the Moderately Low Ability to Achieve Recovery (3) profile relative to the Normative (4) profile.

Outcomes of Profile Membership

Associations between the various profiles and the outcomes considered in the present study are reported in Table 5. The highest levels of burnout and sleeping difficulties were associated with the Low Ability to Achieve Recovery (5) profile, followed by the Moderately Low Ability to Achieve Recovery (3) profile, by the Normative (4) profile, by the Moderately High Ability to Achieve Recovery (1) profile, and finally by the High Ability to Achieve Recovery (2) profile. The Low Ability to Achieve Recovery (5) profile was associated with lower levels of job satisfaction than the Moderately Low Ability to Achieve Recovery (3) and Normative (4) profiles which could not be differentiated from one another. The Moderately High Ability to Achieve Recovery (1) and High Ability to Achieve Recovery (2) profiles, which could not be differentiated from one another, were associated with higher levels of job satisfaction than the Moderately Low Ability to Achieve Recovery (3) and Normative (4) profiles, which could also not be differentiated from one another. The High Ability to Achieve Recovery (2) profile was associated with higher levels of job performance than the Moderately High Ability to Achieve Recovery (1) profile, which itself was associated with higher levels of job performance than the Moderately Low Ability to Achieve Recovery (3) and Low Ability to Achieve Recovery (5) profiles, which could not be differentiated from one another. The High Ability to Achieve Recovery (2) profile was also associated with higher levels of job performance than the Normative (4) profile, which was associated with higher levels of job performance than the Low Ability to Achieve Recovery (5) profile. Supplementary Analyses

To verify whether the differences in results obtained in Study 2 (i.e., the identification of an 
additional Normative profile) were caused by the incorporation of the need for recovery variable as an additional profile indicator (suggesting that the need for recovery might play a distinct role in influencing employees' recovery process) or by random sampling variations (consistent with the idea that all profile indicators reflected a single overarching process), more formal tests of profile similarities were conducted. These tests sought to verify extent to which results would be replicated across studies using only the variables (profile indicators, predictors, and outcomes) that were measured in both studies using the same instruments. These tests were conducted following procedures described in Morin, Meyer et al. (2016): (a) configural similarity (same number of profiles); (b) structural similarity (same profile means); (c) dispersion similarity (same within-profile variability); (d) distributional similarity (same profile size); (e) predictive similarity (same relations with predictors); and (f) explanatory similarity (same relations with outcomes). As noted by Morin, Meyer et al. (2016), profile similarity is supported as long as two indicators out of the CAIC, BIC, and $\mathrm{ABIC}$ are lower when equality constraints are added to a model relative to the previous one. These results are reported in Table S15 of the online supplements (also see Figures S3-S4).

These results from the latent profile analyses conducted on Study 2 sample using only the indicators common to both studies were first consistent with the presence of a solution including either 4 or 5 profiles in Study 2. Tests of profile similarity across studies were thus conducted using both of these solutions. The results associated with the 4-profile solution failed to support the structural similarity of this solution, consistent with the idea that something different was happening in Study 2 relative to Study 1. In contrast, the results associated with the 5-profile solution supported the structural and dispersion similarity of this solution across studies, but not its distributional similarity. These results thus support the presence of five profiles, characterized by the same structure and the same level of within-profile variability across samples, but differing in size. These five profiles were identical to those identified in Study 2 (see Figure S4 of the online supplements) and shared similar associations with predictors (predictive similarity) and outcomes (explanatory similarity), supporting the idea that the need for recovery contributed to the same overarching process as the other profile indicators and was not responsible for the differences in results observed across studies. Rather, this evidence of similarity simply suggested that the non-identification of a Normative profile in Study 1 only reflected random sampling variations, which made it impossible to identify meaningful profiles beyond the fourth one in Study 1. This issue was solved by the reliance on more powerful tests of profile similarity (which double the sample size following the inclusion of equality constraints).

\section{Brief Discussion}

As in Study 1, we identified four profiles presenting clear qualitative differences: Moderately High Ability to Achieve Recovery, Low Ability to Achieve Recovery, Moderately Low Ability to Achieve Recovery, and High Ability to Achieve Recovery. We also identified a fifth profile for which the label Normative was retained to reflect the fact that this profile was the largest, but also reflected a subpopulation of employees whose levels of overcommitment, rumination, need for recovery, and psychological detachment were close to the sample average. Morin et al. (2016) also identified a similar Normative profile of employees presenting average levels across a range of components of psychological health at work. When these five profiles were considered from an outcomes' perspective, the Low Ability to Achieve Recovery profile was associated with the highest levels of burnout and the lowest levels of job satisfaction. In contrast, the High Ability to Achieve Recovery profile was associated with the lowest levels of burnout and sleeping difficulties, and the highest levels of job performance. These results match those from Study 1 and prior research (Sonnentag \& Fritz, 2007, 2015). In addition, global levels of bullying were associated with a lower likelihood of membership into the Moderately High Ability to Achieve Recovery and High Ability to Achieve Recovery profiles relative to the Low Ability to Achieve Recovery, Moderately Low Ability to Achieve Recovery, and Normative profiles. These results are aligned with those from Study 1 and prior research (e.g., Bennett et al., 2016). Finally, and in accordance with Study 1, perceived organizational, supervisor, and colleagues support were unrelated to membership into any of the profiles.

\section{General Discussion}

Overcommitment, rumination, psychological detachment, and need for recovery have long been recognized as distinct, albeit highly correlated, components associated with the work recovery process (e.g., Kinnunen et al., 2017b; Sonnentag \& Fritz, 2015). Yet, very little attention has been devoted to identifying the different configurations taken by these four components among specific profiles of 
employees. As demonstrated in prior studies focusing on employees' work recovery profiles (e.g., Bennett et al., 2016), the adoption of a person-centered approach is naturally suited to the consideration of overcommitment, rumination, psychological detachment, and need for recovery configurations among different subpopulations of workers. Such an approach can also contribute to achieving a more accurate understanding of the joint effects of these four psychological mechanisms on a variety of relevant work outcomes, as well as to the identification of factors involved in the prediction of membership into more desirable profiles.

\section{Profiling Employees' Ability to Achieve Recovery}

First, the results led to the identification of four similar profiles in both studies. Each of these profiles were found to be characterized by corresponding levels across all three (Study 1) or four (Study 2) components, and displaying a High Ability to Achieve Recovery, Moderately High Ability to Achieve Recovery, Moderately Low Ability to Achieve Recovery or Low Ability to Achieve Recovery configuration. The fact that each of these profiles presented matching levels across all four dimensions is consistent with the complementarity of these four components, and with the previous reports of high correlations among them (Potok \& Littman-Ovadia, 2014). Furthermore, the replication of these profiles across studies, despite the added consideration of the need for recovery in Study 2, supports the idea, advanced in the introduction, that these profiles reflect some overarching psychological mechanisms likely to be associated with the work recovery process irrespective of the specific mechanisms considered in their definition. This conclusion also matches the similarity in work recovery profiles identified in previous person-centered studies (e.g., Bennett et al., 2016; Table S1 of the online supplements). Likewise, this observation also reinforces the generalizability of these processes to different samples of employees, and thus their potential utility as guides to the development of generic interventions seeking to facilitate the work recovery process (e.g., Meyer \& Morin, 2016). Yet, it would appear particularly important for future investigations to consider additional profile indicators (e.g., workaholism, work engagement, motivation) and to more extensively assess the situations, occupations, and professional contexts which may lead to more or less pronounced misalignment across components linked to the work recovery process.

Interestingly, a fifth Normative profile, characterized by average levels across all components, was also identified in Study 2. However, the results from supplementary tests of profile similarity suggest that failure to identify this profile in Study 1 might have simply been the results of random sampling variations, rather than the effects of the joint consideration of employees' need for recovery in Study 2. Indeed, these more robust tests did support the similarity of this five-profile solution across samples, even demonstrating the equivalence of associations between these profiles, predictors, and outcomes across studies. The identification of this profile highlights the often-noted importance of replication in person-centered analyses (Meyer \& Morin, 2016). Importantly, this additional profile reveals that, despite the advantages of being able to identify profiles that differ quantitatively and qualitatively from the norm, a large proportion of employees tend to follow that norm, displaying a satisfactory level of functioning that is neither problematic, nor particularly desirable.

\section{Outcomes of Employees' Ability to Achieve Recovery Profiles}

Attesting to their construct validity, the profiles presented well-differentiated associations with the various outcomes. Specifically, employees corresponding to the High Ability to Achieve Recovery profile were found to present the most desirable outcomes levels (i.e., higher levels of job satisfaction and performance, and lower levels of burnout and sleeping difficulties), whereas those corresponding to the Low Ability to Achieve Recovery profile presented the least desirable outcome levels, with the other profiles falling in between these two extremes. These results are consistent with theoretical predictions (Meijman \& Mulder 1998; Sonnentag \& Fritz, 2015) and previous research results (e.g., Huyghebaert et al., 2018), in demonstrating the positive implications of psychological detachment and the detrimental effects of overcommitment, rumination, and need for recovery.

However, and contrary to our expectations, the profiles could not be differentiated from one another in terms of counterproductive work behaviors and absenteeism in Study 1. In addition, although the Moderately Low Ability to Achieve Recovery profile was found to be associated with higher levels of burnout and sleeping difficulties than the Normative profile in Study 2, thus matching our expectations, these two profiles could not be differentiated from one another in regard to job satisfaction and performance. These results suggest that the presence of balanced levels across components associated with the recovery process may be associated with benefits in terms of limiting 
burnout and sleeping difficulties, but not in terms supporting job satisfaction and performance. More generally, our results suggest that the combined role played by overcommitment, rumination, need for recovery, and psychological detachment may differ as a function of the outcomes under study. This observation reinforces the importance for future research to incorporate a broader range of desirable (e.g., extra-role behaviors) and undesirable (e.g., presenteeism) outcomes to better understand the mechanisms at play in these differential effects.

\section{Demographic Characteristics of Employees' Ability to Achieve Recovery Profiles}

Despite the fact that we only considered demographic characteristics as controls in this research, the results revealed noteworthy associations between these characteristics and the profiles. First, and in accordance with the results from previous studies reporting only limited associations between demographic characteristics and recovery experiences (e.g., Schulz et al., 2019), no significant relationship was observed between age or work time and profile membership in both studies.

Second, employees corresponding to the High Ability to Achieve Recovery tended to have more tenure than those corresponding to the Low Ability to Achieve Recovery profile, suggesting that more experienced workers become more efficient at recovering from work (Sluiter et al., 2001). Indeed, with increasing tenure, workers develop more compensation strategies for dealing with their workload and job duties, due to strategies and skills related to their experience and expertise in the working career. Highly tenured employees are also more likely to develop better coping methods or better work adjustment (Mohren et al., 2010). Although purely descriptive in nature, this association between work experiences (i.e., tenure) clearly suggests that efficient work recovery processes are something that can be learned and trained, rather than some fixed individual characteristic.

Third, women were found to be more likely than men to be members of the Low Ability to Achieve Recovery profile relative to the High Ability to Achieve Recovery profile in Study 1, but not in Study 2. It is important to keep in mind that this lack of association found in Study 2 is likely to be related to the specific nature (nurses and nursing assistants) and gender-composition (almost 95\% of women) of this sample, which could have made it harder to detect statistically significant associations. The gender difference found in Study 1 is consistent with prior research demonstrating that women exhibited greater job involvement than men (Lorence, 1987) and indicating that women tend to be more committed to their work roles (Angle \& Perry, 1981). This result suggests that women may need to invest themselves more in their work than men do in order to survive in the workplace (Lee \& Eissenstat, 2018). However, traditional gender-role perspectives also suggest that women tend to be more sensitive to the needs of their family members, often act as providers of comfort or support, and are more affected by the experiences of their family members, thus leading to higher levels of workfamily conflict (Westman et al., 2004). Hence, the perception that their workplaces will support them in their need to manage both their work and their family may increase their recovery experiences, an hypothesis that would be interesting to test in future research.

\section{Predictors of Employees' Ability to Achieve Recovery Profiles}

A final objective of this research was to investigate the role of a set of hindrance job demands (i.e., emotional dissonance, workload, and bullying) and job resources (perceived organizational support, supervisor support, and colleagues support) in the prediction of profile membership. In both studies, our results showed that hindrance demands (i.e., workload, emotional dissonance, global levels of bullying, and specific levels of work-related bullying) were associated with a higher likelihood of membership into the Low Ability to Achieve Recovery profile relative to the other ones. These results match those from past studies showing hindrance demands to decrease psychological detachment, and to foster rumination, overcommitment, and need for recovery (Bennett et al., 2016; Huyghebaert et al., 2018). This interpretation is also consistent with the idea that the persistent activation of psychophysiological systems associated with hindrance demands tends to interfere with the work recovery processes (Sonnentag \& Bayer, 2005).

In Study 2, global levels of bullying and specific levels of work-related bullying were also associated with a decreased likelihood of membership into the Moderately High Ability to Achieve Recovery and High Ability to Achieve Recovery profiles, relative to the Normative profile. This difference is consistent with prior research demonstrating that bullying is negatively related to recovery experiences (e.g., Rodríguez-Muñoz et al., 2017). What the present results show, however, is that this association seems to be mainly focused on reducing the likelihood of being able to achieve optimal work recovery experiences (i.e., by decreasing the likelihood of membership into the two most 
desirable profiles), rather than increasing the likelihood of experiencing particularly bad work recovery processes (i.e., by increasing the likelihood of membership into the two least desirable profiles). However, specific levels of person-related bullying and physically-intimidating bullying were unrelated to the likelihood of membership into any of the profiles, suggesting that global levels of bullying and specific levels of work-related bullying were the key drivers of these associations.

In terms of job resources, both studies failed to support previous research (e.g., Bennett et al., 2016), revealing a lack of associations between employees' perceptions of organizational, supervisor, and colleagues support and their likelihood of membership into the various profiles. Liu et al. (2011) suggested that the interpretation by employees of social support and consequently their levels of psychological detachment, rumination, overcommitment, and need for recovery may depend on the idiosyncrasy of this support relative to the levels of support received by his/her colleagues. Thus, perceived equity in terms of social support may moderate the relations between employees' perceptions of social support and the profile indicators used in the present research, such that the effects of perceived organizational, supervisor, and colleagues support on psychological detachment, rumination, overcommitment, and need for recovery might be stronger when equity is greater or more favorable to the targeted employee. In addition, a favorable level of inequity (when an employee perceives being exposed to more desirable practices than his or her colleagues) might indicate a more idiosyncratic relationship with the support provider (Boies \& Howell, 2006), leading employees to value this support more, thus strengthening the positive relation between support and psychological detachment, and the negative relations between support and rumination, overcommitment, and need for recovery. More generally, it would be interesting for future research to devote more attention to unpacking the mechanisms involved in social support at work as recent studies suggest that different sources of social support may be associated with detrimental outcomes (e.g., Gillet et al., 2017).

Part of this unexpected result on the effects of social support in the present research could also be related to our consideration of workplace support perceptions simultaneously with a variety of hindrance stressors likely to decrease their potency. Indeed, support helps to decrease work related stress (Bakker \& Demerouti, 2007) and multivariate analyses such as those used in the present research are focused on the unique contribution of each predictor net of what it shares with the others. It would be interesting for future research to devote more attention to unpacking the various mechanisms involved in social support at work, and to do so while using a greater variety of social support measures. Indeed, even if perceived organizational, supervisor, and colleagues support are explicitly conceptualized as perceptual (de Vos et al., 2009), they might be impacted by social desirability and self-report biases. It would be interesting for future research to rely on more objective data as well as informant measures of social support at work. Future research should also examine whether additional personal and job resources might influence profile membership (e.g., job crafting, work autonomous motivation, job variety, job autonomy, and job control; e.g., Bennett et al., 2018).

\section{Limitations and Directions for Future Research}

Limitations have to be kept in mind when considering the implications of the present results. First, this research relied on self-report measures, which could be impacted by self-report biases and social desirability. It would be highly informative for future studies to expand on the current results using more objective measures (e.g., physiological measures of stress, official turnover data), coupled with informant (e.g., supervisors, colleagues) reports of work engagement and performance. Second, we used a single item to assess job satisfaction, performance, and absenteeism. When compared to multiitem measures, single-item measures tend to be more unreliable and to provide a more limited content coverage. Although the results from our tests of invariance supported the equivalence of this scale across studies, the value of Cronbach's alpha for perceived organizational support in Study 2 was low (.58). For these reasons, it would be interesting to seek to replicate the results from the current research with more solid measurement scales and objective performance and absenteeism data.

Third, our treatment of the covariables as either predictors (i.e., workload, emotional dissonance, bullying, perceived organizational support, supervisor support, and colleagues support) or outcomes (i.e., burnout, sleeping difficulties, job satisfaction, job performance, counter-productive work behaviors, and absenteeism) was based on theoretical (e.g., Bennett et al., 2018; Sonnentag \& Fritz, 2015) and statistical (Meyer \& Morin, 2016) considerations. However, our research design and the limitations inherent to our analytical method did not allow us to assess reversed causality, reciprocal influence, or spurious associations, nor the possible role of profile membership in the prediction of 
changes in outcome levels. Yet, burnout might be considered as a predictor of profile membership as it is associated with a decrease in psychological detachment from work during off-job time over several weeks (Sonnentag et al., 2014). Similarly, job performance may predict rumination (Vahle-Hinz et al., 2017) and also be included as a predictor of profile membership. Therefore, future research would gain from examining more systematically the direction of the associations among covariates and profiles within the context of a longitudinal research design. Longitudinal research also makes it possible to address the joint issues of within-person and within-sample profile stability (Kam et al., 2016).

\section{Practical Implications}

Despite these limitations and pending replication, our results suggest that managers should be particularly attentive to employees displaying Moderately Low Ability to Achieve Recovery or Low Ability to Achieve Recovery profiles. Indeed, these workers appeared to be at risk for multiple difficulties (e.g., burnout, sleeping difficulties), and to represent a relatively numerous subpopulation of employees (30.12\% to $43.88 \%$ across studies). However, although the Normative profile identified in Study 2 did display more desirable outcome levels than the Moderately Low Ability to Achieve Recovery or Low Ability to Achieve Recovery profiles, it is important to reinforce that this rather large (35.47\%) profile also displayed outcome levels that fell below those observed in the Moderately High Ability to Achieve Recovery and High Ability to Achieve Recovery profiles. This observation is important, not only as it reinforces the fact that close to (Study 1) or more than (Study 2) half of the employees seem to display a profile carrying at least some level of risk, but also in reinforcing the need for organizations to work at maximizing efficient recovery for all employees, rather than simply trying to help employees displaying a problematic profile.

In particular, our results highlighted the role of hindrance job demands, including emotional dissonance, workload, and bullying, in driving membership into the least desirable profiles, and the limited role of job resources (workplace support) at supporting more efficient profiles. This observation highlights the importance of intervening to maximally reduce exposure to such hindrance demands, including workplace bullying. Likewise, organizations should be careful in monitoring workload distribution to ensure that this organizational demand do not get too high, for they would hinder the work recovery process and trigger a chain of negative consequences for both individuals and organizations (Huyghebaert et al., 2018). Organizations should also avoid situations that create emotional dissonance to facilitate workers' ability to achieve recovery.

\section{References}

Albrecht, S.L. (2015). Challenge demands, hindrance demands, and psychological need satisfaction: Their influence on employee engagement and emotional exhaustion. Journal of Personnel Psychology, 14, 70-79. https://doi.org/10.1027/1866-5888/a000122

Angle, H.L., \& Perry, J.L. (1981). An empirical assessment of organizational commitment and organizational effectiveness. Administrative Science Quarterly, 26, 1-14. https://doi.org/10.2307/2392596

Asparouhov, T. \& Muthén, B.O. (2015). Auxiliary variables in mixture modeling: Using the BCH method in Mplus to estimate a distal outcome model and an arbitrary secondary model (Mplus Web Note \#21). https://www.statmodel.com/download/asparouhov_muthen_2014.pdf

Bakk, Z., Tekle, F.T., \& Vermunt, J.K. (2013). Estimating the association between latent class membership and external variables using bias-adjusted three-step approaches. Sociological Methodology, 43, 272-311. https://doi.org/10.1177/0081175012470644

Bakker, A.B., \& Demerouti, E. (2007). The Job Demands-Resources model: State of the art. Journal of Managerial Psychology, 22, 309-328. https://doi.org/10.1108/02683940710733115

Bennett, A.A., Bakker, A.B., \& Field, J.G. (2018). Recovery from work-related effort: A meta-analysis. Journal of Organizational Behavior, 39, 262-275. https://doi.org/10.1002/job.2217

Bennett, A.A., Gabriel, A.S., Calderwood, C., Dahling, J.J., \& Trougakos, J.P. (2016). Better together? Examining profiles of employee recovery experiences. Journal of Applied Psychology, 101, 1635-1654. https://doi.org/10.1037/ap10000157

Boies, K., \& Howell, J.M. (2006). Leader-member exchange in teams: An examination of the interaction between relationship differentiation and mean LMX in explaining team-level outcomes. The Leadership Quarterly, 17, 246-257. https://doi.org/10.1016/j.leaqua.2006.02.004

Caesens, G., Stinglhamber, F., \& Luypaert, G. (2014). The impact of work engagement and workaholism on well-being: The role of work-related social support. The Career Development 
International, 19, 813-835. https://doi.org/10.1108/CDI-09-2013-0114

de Bloom, J., Radstaak, M., \& Geurts, S. (2014). Vacation effects on behaviour, cognition and emotions of compulsive and non-compulsive workers: Do obsessive workers go 'cold Turkey'? Stress and Health, 30, 232-243. https://doi.org/10.1002/smi.2600

de Vos, A., de Stobbeleir, K., \& Meganck, A. (2009). The relationship between career-related antecedents and graduates' anticipatory psychological contracts. Journal of Business and Psychology, 24, 289-298. https://doi.org/10.1007/s10869-009-9107-3

Demsky, C.A., Fritz, C., Hammer, L.B., \& Black, A.E. (2019). Workplace incivility and employee sleep: The role of rumination and recovery experiences. Journal of Occupational Health Psychology, 24, 228-240. https://doi.org/10.1037/ocp0000116

Diallo, T.M.O, Morin, A.J.S., \& Lu, H. (2017). The impact of total and partial inclusion or exclusion of active and inactive time invariant covariates in growth mixture models. Psychological Methods, 22, 166-190. https://doi.org/10.1037/met0000084

Einarsen, S., Hoel, H., \& Notelaers, G. (2009). Measuring exposure to bullying and harassment at work: Validity, factor structure and psychometric properties of the Negative Acts QuestionnaireRevised. Work \& Stress, 23, 24-44. https://doi.org/10.1080/02678370902815673

Eisenberger, R., Huntington, R., Hutchison, S., \& Sowa, D. (1986). Perceived organizational support. Journal of Applied Psychology, 71, 500-507. https://doi.org/10.1037/0021-9010.71.3.500

Enders, C.K. (2010). Applied missing data analysis. Guilford.

Feuerhahn, N., Kühnel, J., \& Kudielka, B.M. (2012). Interaction effects of effort-reward imbalance and overcommitment on emotional exhaustion and job performance. International Journal of Stress Management, 19, 105-131. https://doi.org/10.1037/a0028338

Gillet, N., Gagné, M., Sauvagère, S., \& Fouquereau, E. (2013). The role of supervisor autonomy support, organizational support, and autonomous and controlled motivation in predicting employees' satisfaction and turnover intentions. European Journal of Work and Organizational Psychology, 22, 450-460. https://doi.org/10.1080/1359432X.2012.665228

Gillet, N., Huyghebaert-Zouaghi, T., Réveillère, C., Colombat, P., \& Fouquereau, E. (2020). The effects of job demands on nurses' burnout and presenteeism through sleep quality and relaxation. Journal of Clinical Nursing, 29, 583-592. https://doi.org/10.1111/jocn.15116

Gillet, N., Morin, A.J.S., Cougot, B., \& Gagné, M. (2017). Workaholism profiles: Associations with determinants, correlates, and outcomes. Journal of Occupational \& Organizational Psychology, 90, 559-586. https://doi.org/10.1111/joop.12185

Hipp, J.R., \& Bauer, D.J. (2006). Local solutions in the estimation of growth mixture models. Psychological Methods, 11,36-53. https://doi.org/10.1037/1082-989X.11.1.36

Huyghebaert, T., Gillet, N., Beltou, N., Tellier, F., \& Fouquereau, E. (2018). Effects of workload on teachers' functioning: A moderated mediation model including sleeping problems and overcommitment. Stress and Health, 34, 601-611. https://doi.org/10.1002/smi.2820

Iordache, S., Elseviers, M., De Cock, R., \& Van Rompaey, B. (2020). Development and validation of an assessment for nursing workload in emergency departments. Journal of Clinical Nursing, 29, 794-809. https://doi.org/10.1111/jocn.15106

Jenkins, C.D., Stanton, B.A., Niemcryk, S.J., \& Rose, R.M. (1988). A scale for the estimation of sleep problems in clinical research. Journal of Clinical Epidemiology, 41, 313-321. https://doi.org/10.1016/0895-4356(88)90138-2

Johnson, S.L. (2009). International perspectives on workplace bullying among nurses: A review. International Nursing Review, 56, 34-40. https://doi.org/10.1111/j.1466-7657.2008.00679.x

Kam, C., Morin, A.J.S., Meyer, J.P., \& Topolnytsky, L. (2016). Are commitment profiles stable and predictable? A latent transition analysis. Journal of Management, 42, 1462-1490. https://doi.org/10.1177/0149206313503010

Kessler, R.C., Barber, C., Beck, A., Berglund, P., Cleary, P.D., McKenas, D., ... Wang, P. (2003). The World Health Organization Health and Work Performance Questionnaire (HPQ). Journal of Occupational and Environmental Medicine, 45, 156-174. https://doi.org/10.1097/01.jom.0000052967.43131.51

Kinnunen, U., Feldt, T., de Bloom, J., Sianoja, M., Korpela, K., \& Geurts, S. (2017a). Linking boundary crossing from work to nonwork to work-related rumination across time: A variable- and person-oriented approach. Journal of Occupational Health Psychology, 22, 467-480. 
https://doi.org/10.1037/ocp0000037

Kinnunen, U., Feldt, T., Sianoja, M., de Bloom, J., Korpela, K., \& Geurts, S. (2017b). Identifying long-term patterns of work-related rumination: Associations with job demands and well-being outcomes. European Journal of Work and Organizational Psychology, 26, 514-526. https://doi.org/10.1080/1359432X.2017.1314265

Kinnunen, U., Rantanen, J., de Bloom, J., Mauno, S., Feldt, T., \& Korpela, K. (2016). The role of work-nonwork boundary management in work stress recovery. International Journal of Stress Management, 23, 99-123. https://doi.org/10.1037/a0039730

Lee, Y., \& Eissenstat, S.J. (2018). An application of work engagement in the job demands-resources model to career development: Assessing gender differences. Human Resource Development Quarterly, 29, 143-161. https://doi.org/10.1002/hrdq.21310

LePine, J.A., Podsakoff, N.P., \& LePine, M.A. (2005). A meta-analytic test of the challenge stressorhindrance stressor framework: An explanation for inconsistent relationships among stressors and $\begin{array}{llll}\text { performance. Academy of Management Journal, 48, 764-775. } & \text {. }\end{array}$ https://doi.org/10.5465/AMJ.2005.18803921

Liu, D., Zhang, S., Wang, L., \& Lee, T. W. (2011). The effects of autonomy and empowerment on employee turnover: Test of a multilevel model in teams. Journal of Applied Psychology, 96, 13051316. https://doi.org/10.1037/a0024518

Lo, Y., Mendell, N., \& Rubin, D. (2001). Testing the number of components in a normal mixture. Biometrika, 88, 767-778. https://doi.org/10.1093/biomet/88.3.767

Lorence, J. (1987). A test of "gender" and "job" models of sex differences in job involvement. Social Forces, 66, 121-142. https://doi.org/10.2307/2578903

Marsh, H.W., Lüdtke, O., Trautwein, U., \& Morin, A.J.S. (2009). Classical latent profile analysis of academic self-concept dimensions: Synergy of person- and variable-centered approaches to theoretical models of self-concept. Structural Equation Modeling, 16, 191-225. https://doi.org/10.1080/10705510902751010

Meijman, T.F., \& Mulder, G. (1998). Psychological aspects of workload. In P.J.D. Drenth, H. Thierry, \& C.J. de Wolff (Eds.), Handbook of work and organizational: Work psychology (pp. 5-33). Psychology Press.

Meyer, J.P., \& Morin, A.J.S. (2016). A person-centered approach to commitment research: Theory, research, and methodology. Journal of Organizational Behavior, 37, 584-612. https://doi.org/10.1002/job.2085

Mohren, D.C., Jansen, N., \& Kant, I. (2010). Need for recovery from work in relation to age: A prospective cohort study. International Archives of Occupational \& Environmental Health, 83, 553-561. https://doi.org/10.1007/s00420-009-0491-9

Morin, A.J.S., \& Litalien, D. (2019). Mixture modelling for lifespan developmental research. In Oxford Research Encyclopedia of Psychology. Oxford University Press.

Morin, A.J.S., Boudrias, J.-S., Marsh, H.W., Madore, I., \& Desrumaux, P. (2016). Further reflections on disentangling shape and level effects in person-centered analyses: An illustration exploring the dimensionality of psychological health. Structural Equation Modeling, 23, 438-454. https://doi.org/10.1080/10705511.2015.1116077

Muthén, L.K., \& Muthén, B. (2017). Mplus user's guide. Muthén \& Muthén.

Peugh, J., \& Fan, X. (2013). Modeling unobserved heterogeneity using latent profile analysis: A Monte Carlo simulation. Structural Equation Modeling, 20, 616-639. https://doi.org/10.1080/10705511.2013.824780

Potok, Y., \& Littman-Ovadia, H. (2014). Does personality regulate the work stressor-psychological detachment relationship? Journal of Career Assessment, 22, 43-58. https://doi.org/10.1177/1069072713487853

Rivkin, W., Diestel, S., \& Schmidt, K.-H. (2015). Psychological detachment: A moderator in the relationship of self-control demands and job strain. European Journal of Work and Organizational Psychology, 24, 376-388. https://doi.org/10.1080/1359432X.2014.924926

Rodríguez-Muñoz, A., Antino, M., \& Sanz-Vergel, A.I. (2017). Cross-domain consequences of workplace bullying: A multi-source daily diary study. Work \& Stress, 31, 297-314. https://doi.org/10.1080/02678373.2017.1330782

Rydstedt, L.W., Cropley, M., Devereux, J.J., \& Michalianou, G. (2009). The effects of gender, long- 
term need for recovery and trait inhibition-rumination on morning and evening saliva cortisol secretion. Anxiety, Stress \& Coping: An International Journal, 22, 465-474. https://doi.org/10.1080/10615800802596378

Schaufeli, W.B., Leiter, M.P., Maslach, C., \& Jackson, S.E. (1996). The Maslach Burnout InventoryGeneral Survey. In C. Maslach, S.E. Jackson, \& M.P. Leiter (Eds.), Maslach Burnout Inventory $3^{\text {rd }}$ ed. (pp. 19-26). Consulting Psychologists Press.

Schulz, A.D., Schöllgen, I., \& Fay, D. (2019). The role of resources in the stressor-detachment model. International Journal of Stress Management, 26, 306-314. https://doi.org/10.1037/str0000100

Shimazu, A., Schaufeli, W.B., Kamiyama, K., \& Kawakami, N. (2015). Workaholism vs. work engagement: The two different predictors of future well-being and performance. International Journal of Behavioral Medicine, 22, 18-23. https://doi.org/10.1007/s12529-014-9410-x

Siegrist, J. (1996). Adverse health effects of high-effort/low-reward conditions. Journal of Occupational Health Psychology, 1, 27-41. https://doi.org/10.1037/1076-8998.1.1.27

Siegrist, J. (2001). A theory of occupational stress. In J. Dunham (Ed.), Stress in the workplace: Past, present and future (pp. 52-66). Whurr Publishers.

Sluiter, J.K., Frings-Dresen, M.H.W., van der Beek, A.J., \& Meijman, T.F. (2001). The relation between work-induced neuroendocrine reactivity and recovery, subjective need for recovery, and health status. Journal of Psychosomatic Research, 50, 29-37. https://doi.org/10.1016/S00223999(00)00213-0

Sluiter, J.K., van der Beek, A.J., \& Frings-Dresen, M.H.W. (1999). The influence of work characteristics on the need for recovery and experienced health: A study on coach drivers. Ergonomics, 42, 573-583. https://doi.org/10.1080/001401399185487

Sonnentag, S., \& Bayer, U.-V. (2005). Switching off mentally: Predictors and consequences of psychological detachment from work during off-job time. Journal of Occupational Health Psychology, 10, 393-414. https://doi.org/10.1037/1076-8998.10.4.393

Sonnentag, S., \& Fritz, C. (2007). The Recovery Experience Questionnaire: Development and validation of a measure for assessing recuperation and unwinding from work. Journal of Occupational Health Psychology, 12, 204-221. https://doi.org/10.1037/1076-8998.12.3.204

Sonnentag, S., \& Fritz, C. (2015). Recovery from job stress: The stressor-detachment model as an integrative framework. Journal of Organizational Behavior, 36, S72-S103. https://doi.org/10.1002/job.1924

Sonnentag, S., Arbeus, H., Mahn, C., \& Fritz, C. (2014). Exhaustion and lack of psychological detachment from work during off-job time: Moderator effects of time pressure and leisure experiences. Journal of Occupational Health Psychology, 19, 206-216. https://doi.org/10.1037/a0035760

Spector, P.E., \& Jex, S.M. (1998). Development of four self-report measures of job stressors and strain: Interpersonal Conflict at Work Scale, Organizational Constraints Scale, Quantitative Workload Inventory, and Physical Symptoms Inventory. Journal of Occupational Health Psychology, 3, 356-367. https://doi.org/10.1037/1076-8998.3.4.356

Spector, P.E., Bauer, J.A., \& Fox, S. (2010). Measurement artifacts in the assessment of counterproductive work behavior and organizational citizenship behavior: Do we know what we think we know? Journal of Applied Psychology, 95, 781-790. https://doi.org/10.1037/a0019477

ten Brummelhuis, L.L., \& Bakker, A.B. (2012). A resource perspective on the work-home interface: The work-home resources model. American Psychologist, 67, 545-556. https://doi.org/10.1037/a0027974

Vahle-Hinz, T., Mauno, S., de Bloom, J., \& Kinnunen, U. (2017). Rumination for innovation? Analysing the longitudinal effects of work-related rumination on creativity at work and off-job recovery. Work \& Stress, 31, 315-337. https://doi.org/10.1080/02678373.2017.1303761

van Veldhoven, M., \& Broersen, S. (2003). Measurement quality and validity of the "Need for recovery scale". Occupational and Environmental Medicine, 60, 3-9. https://doi.org/10.1136/oem.60.suppl_1.i3

van Wijhe, C., Peeters, M., Schaufeli, W., \& Ouweneel, E. (2013). Rise and shine: Recovery experiences of workaholic and nonworkaholic employees. European Journal of Work and Organizational Psychology, 22, 476-489. https://doi.org/10.1080/1359432X.2012.663527

Westman, M., Vinokur, A.D., Hamilton, V.L., \& Roziner, I. (2004). Crossover of marital 
dissatisfaction during military downsizing among Russian army officers and their spouses. Journal of Applied Psychology, 89, 769-779. https://doi.org/10.1037/0021-9010.89.5.769

Wirtz, N., Rigotti, T., Otto, K., \& Loeb, C. (2017). What about the leader? Crossover of emotional exhaustion and work engagement from followers to leaders. Journal of Occupational Health Psychology, 22, 86-97. https://doi.org/10.1037/ocp0000024

Xanthopoulou, D., Bakker, A.B., Oerlemans, W.G.M., \& Koszucka, M. (2018). Need for recovery after emotional labor: Differential effects of daily deep and surface acting. Journal of Organizational Behavior, 39, 481-494. https://doi.org/10.1002/job.2245

Zapf, D., Vogt, C., Seifert, C., Mertini, H., \& Isic, A. (1999). Emotion work as a source of stress: The concept and development of an instrument. European Journal of Work and Organizational Psychology, 8, 371-400. https://doi.org/10.1080/135943299398230 


\section{Figure 1}

Final Four-Profile Solution in Study 1

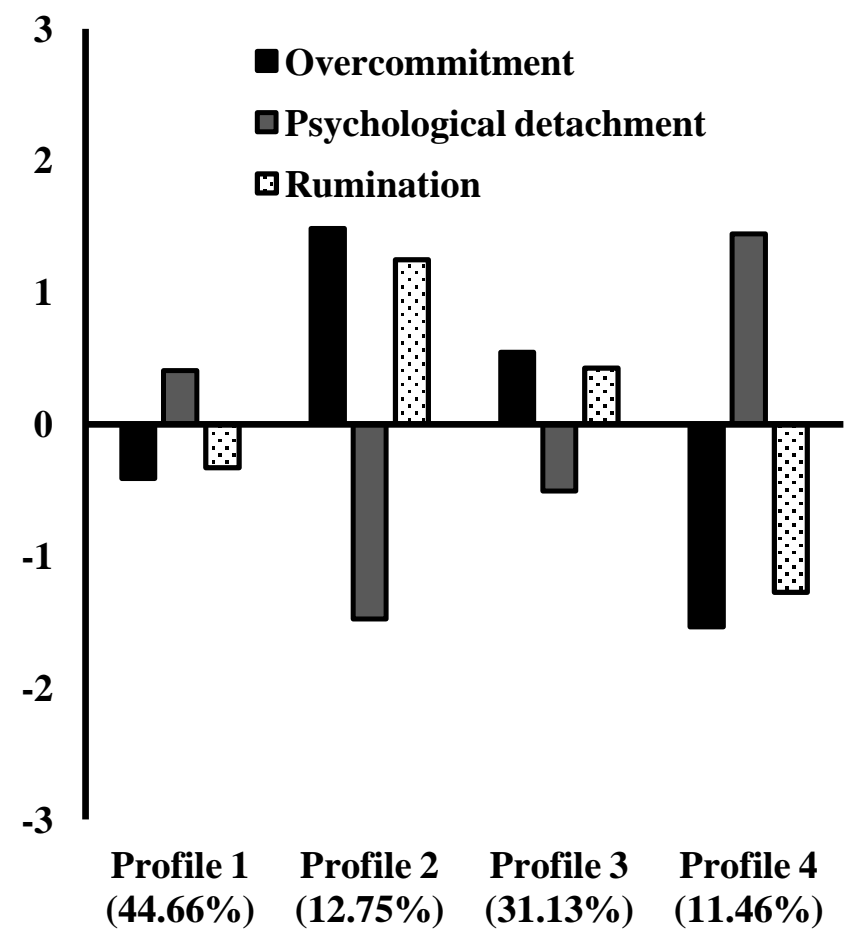

Note. Overcommitment, psychological detachment, and rumination are factor scores with a mean of 0 and a standard deviation of 1 in the total sample; Profile 1: Moderately High Ability to Achieve Recovery; Profile 2: Low Ability to Achieve Recovery; Profile 3: Moderately Low Ability to Achieve Recovery; Profile 4: High Ability to Achieve Recovery. 
Figure 2

Final Five-Profile Solution in Study 2

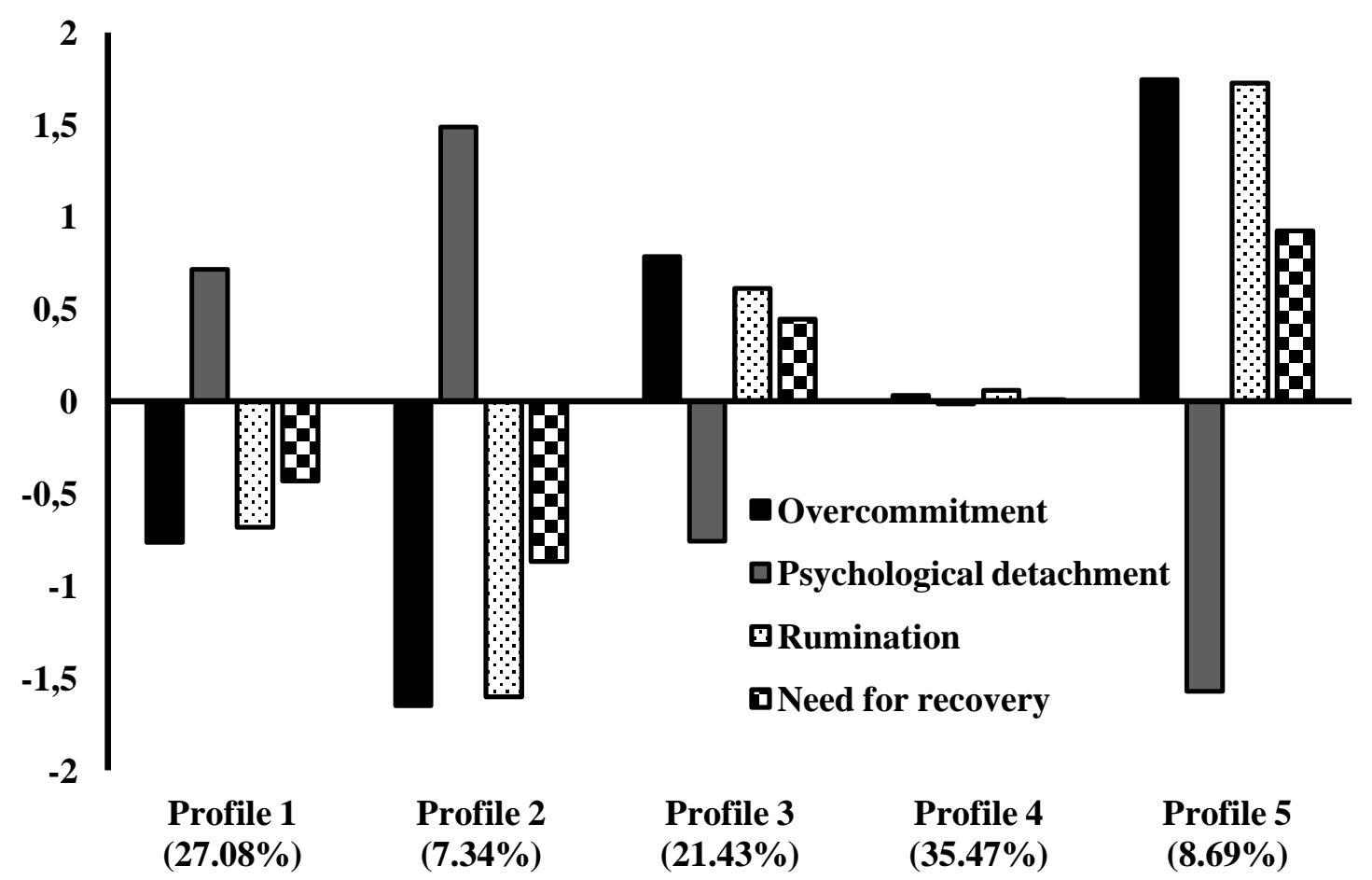

Note. Overcommitment, psychological detachment, rumination, and need for recovery are factor scores with a mean of 0 and a standard deviation of 1 in the total sample; Profile 1: Moderately High Ability to Achieve Recovery; Profile 2: High Ability to Achieve Recovery; Profile 3: Moderately Low Ability to Achieve Recovery; Profile 4: Normative; Profile 5: Low Ability to Achieve Recovery. 


\section{Table 1}

Results from the Latent Profile Analysis Models

\begin{tabular}{lcccccccccc}
\hline Model & LL & $\# f p$ & Scaling & AIC & CAIC & BIC & ABIC & Entropy & aLMR & BLRT \\
\hline Study 1 & & & & & & & & & & \\
1 Profile & -1658.276 & 6 & 0.911 & 3328.551 & 3358.721 & 3352.721 & 3333.681 & Na & Na & Na \\
2 Profiles & -1416.842 & 13 & 1.089 & 2859.684 & 2925.052 & 2912.052 & 2870.800 & .808 & $<.001$ & $<.001$ \\
3 Profiles & -1294.561 & 20 & 1.281 & 2629.122 & 2729.688 & 2709.688 & 2646.223 & .864 & .005 & $<.001$ \\
4 Profiles & -1193.998 & 27 & 1.167 & 2441.997 & 2577.760 & 2550.760 & 2465.083 & .885 & $<.001$ & $<.001$ \\
5 Profiles & -1153.833 & 34 & 1.063 & 2375.666 & 2546.627 & 2512.627 & 2404.737 & .899 & .020 & $<.001$ \\
6 Profiles & -1116.559 & 41 & 1.039 & 2315.117 & 2521.277 & 2480.277 & 2350.174 & .907 & .199 & $<.001$ \\
7 Profiles & -1096.227 & 48 & 1.052 & 2288.454 & 2529.811 & 2481.811 & 2329.495 & .902 & .026 & $<.001$ \\
8 Profiles & -1072.905 & 55 & 0.977 & 2255.809 & 2532.364 & 2477.364 & 2302.836 & .911 & .153 & $<.001$ \\
Study 2 & & & & & & & \\
1 Profile & -2199.328 & 8 & 0.957 & 4414.656 & 4454.883 & 4446.883 & 4421.497 & $\mathrm{Na}$ & $\mathrm{Na}$ & $\mathrm{Na}$ \\
2 Profiles & -1914.985 & 17 & 1.738 & 3863.971 & 3949.452 & 3932.452 & 3878.506 & .779 & .169 & $<.001$ \\
3 Profiles & -1689.315 & 26 & 1.090 & 3430.630 & 3561.365 & 3535.365 & 3452.861 & .884 & $<.001$ & $<.001$ \\
4 Profiles & -1615.793 & 35 & 1.141 & 3301.586 & 3477.575 & 3442.575 & 3331.512 & .871 & .038 & $<.001$ \\
5 Profiles & -1561.266 & 44 & 1.255 & 3210.532 & 3431.777 & 3387.777 & 3248.154 & .870 & .354 & $<.001$ \\
6 Profiles & -1514.077 & 53 & 1.386 & 3134.154 & 3400.653 & 3347.653 & 3179.471 & .884 & .600 & $<.001$ \\
7 Profiles & -1476.904 & 62 & 1.061 & 3077.808 & 3389.561 & 3327.561 & 3130.820 & .884 & .010 & $<.001$ \\
8 Profiles & -1450.632 & 71 & 1.039 & 3043.264 & 3400.272 & 3329.272 & 3103.972 & .889 & .120 & $<.001$ \\
\hline
\end{tabular}

Note. LL: Model LogLikelihood; \#fp: Number of free parameters; Scaling: Scaling factor associated with MLR loglikelihood estimates; AIC: Akaïke Information Criteria; CAIC: Constant AIC; BIC: Bayesian Information Criteria; ABIC: Sample-size adjusted BIC; aLMR: Adjusted Lo-Mendel-Rubin likelihood ratio test; BLRT: Bootstrap Likelihood Ratio Test. 
Table 2

Results from Multinomial Logistic Regressions for the Effects of the Predictors and Demographic Variables on Profile Membership (Study 1)

\begin{tabular}{|c|c|c|c|c|c|c|}
\hline & \multicolumn{2}{|c|}{ Profile 1 vs. Profile 4} & \multicolumn{2}{|c|}{ Profile 2 vs. Profile 4} & \multicolumn{2}{|c|}{ Profile 3 vs. Profile 4} \\
\hline & Coef. (SE) & OR & Coef. (SE) & OR & Coef. (SE) & OR \\
\hline POS & $.426(.341)$ & 1.531 & $.681(.468)$ & 1.976 & $.629(.384)$ & 1.876 \\
\hline PSS & $-.067(.332)$ & .935 & $-.474(.447)$ & .623 & $-.378(.372)$ & .685 \\
\hline PCS & $.268(.271)$ & 1.307 & $.349(.348)$ & 1.418 & $.362(.279)$ & 1.436 \\
\hline Workload & $.558(.236)^{*}$ & 1.747 & $1.539(.348)^{* *}$ & 4.660 & $.784(.262)^{* *}$ & 2.190 \\
\hline ED & $.475(.278)$ & 1.608 & $1.160(.358)^{* *}$ & 3.190 & $.700(.291)^{*}$ & 2.014 \\
\hline Sex & $.644(.434)$ & 1.904 & $1.441(.690)^{*}$ & 4.225 & $.638(.474)$ & 1.893 \\
\hline Age & $.063(.221)$ & 1.065 & $.529(.313)$ & 1.697 & $.234(.238)$ & 1.264 \\
\hline Education & $.064(.222)$ & 1.066 & $.499(.321)$ & 1.647 & $.358(.257)$ & 1.430 \\
\hline Public/Private & $-.681(.466)$ & .506 & $-.950(.593)$ & .387 & $-1.660(.496)^{* *}$ & 190 \\
\hline Work time & $.074(.476)$ & 1.077 & $-.350(.611)$ & .705 & $.043(.504)$ & 1.044 \\
\hline \multirow[t]{3}{*}{ Tenure position } & $-.381(.177)^{*}$ & .683 & $-.670(.281)^{*}$ & .512 & $-.560(.206)^{* *}$ & .571 \\
\hline & \multicolumn{2}{|c|}{ Profile 1 vs. Profile 3} & \multicolumn{2}{|c|}{ Profile 2 vs. Profile 3} & \multicolumn{2}{|c|}{ Profile 1 vs. Profile 2} \\
\hline & Coef. (SE) & OR & Coef. (SE) & OR & Coef. (SE) & OR \\
\hline POS & $-.203(.296)$ & .816 & $.051(.393)$ & 1.052 & $-.254(.385)$ & .776 \\
\hline PSS & $.311(.272)$ & 1.365 & $-.096(.364)$ & .908 & $.407(.356)$ & 1.502 \\
\hline PCS & $-.094(.133)$ & .910 & $-.013(.241)$ & 987 & $-.081(.235)$ & 922 \\
\hline Workload & $-.226(.184)$ & .798 & $.755(.294)^{* *}$ & 2.128 & $-.981(.285)^{* *}$ & .375 \\
\hline ED & $-.225(.167)$ & .799 & $.460(.259)$ & 1.584 & $-.685(.260) * *$ & .504 \\
\hline Sex & $.006(.384)$ & 1.006 & $.803(.621)$ & 2.232 & $-.797(.613)$ & 451 \\
\hline Age & $-.171(.162)$ & .843 & $.295(.264)$ & 1.343 & $-.466(.250)$ & .628 \\
\hline Education & $-.294(.193)$ & .745 & $.141(.285)$ & 1.151 & $-.435(.259)$ & 647 \\
\hline Public/Private & $.979(.316)^{* *}$ & 2.662 & $.710(.424)$ & 2.034 & $.268(.411)$ & 1.307 \\
\hline Work time & $.031(.328)$ & 1.031 & $-.393(.473)$ & .675 & $.424(.449)$ & 1.528 \\
\hline Tenure position & $.180(.165)$ & 1.197 & $-.109(.265)$ & .897 & $.289(.248)$ & 1.335 \\
\hline
\end{tabular}

Note. $* p<.05 ; * *<<.01$; SE: Standard Error of the coefficient; OR: Odds Ratio; POS: Perceived

Organizational Support; PSS: Perceived Supervisor Support; PCS: Perceived Colleagues Support; ED:

Emotional Dissonance; indicators of POS, PSS, PCS, workload, and ED are estimated from factor scores with a mean of 0 and a standard deviation of 1 in the total sample; age and tenure have been standardized prior to the analyses; sex: 0 male and 1 female; work time: 0 full time and 1 part time; the coefficients and OR reflect the effects of the predictors on the likelihood of membership into the first listed profile relative to the second listed profile; Profile 1: Moderately High Ability to Achieve Recovery; Profile 2: Low Ability to Achieve Recovery; Profile 3: Moderately Low Ability to Achieve Recovery; Profile 4: High Ability to Achieve Recovery. 
Table 3

Results from Multinomial Logistic Regressions for the Effects of the Predictors and Demographic Variables on Profile Membership (Study 2)

\begin{tabular}{|c|c|c|c|c|c|c|c|c|c|c|}
\hline & \multicolumn{2}{|c|}{ Profile 1 vs. Profile 5} & \multicolumn{2}{|c|}{ Profile 2 vs. Profile 5} & \multicolumn{2}{|c|}{ Profile 3 vs. Profile 5} & \multicolumn{2}{|c|}{ Profile 4 vs. Profile 5} & \multicolumn{2}{|c|}{ Profile 1 vs. Profile 4} \\
\hline & Coef. (SE) & OR & Coef. (SE) & OR & Coef. (SE) & OR & Coef. (SE) & OR & Coef. (SE) & OR \\
\hline PRB (S-factor) & $-.040(.359)$ & .961 & $-.289(.474)$ & .749 & $-.320(.352)$ & .726 & $-.379(.324)$ & .685 & $.339(.270)$ & 1.404 \\
\hline WRB (S-factor) & $-1.145(.426)^{* *}$ & .318 & $-2.317(.565)^{* *}$ & .099 & $-.532(.430)$ & .587 & $-.703(.343)^{*}$ & .495 & $-.442(.216)^{*}$ & .643 \\
\hline PIB (S-factor) & $-.509(.558)$ & .601 & $-.874(.880)$ & .417 & $-.235(.470)$ & .791 & $-.396(.448)$ & 673 & $-.113(.423)$ & .893 \\
\hline GB (G-Factor) & $-.945(.306) * *$ & .389 & $-1.318(.540)^{*}$ & .268 & $.200(.297)$ & 1.221 & $-.317(.261)$ & .728 & $-.628(.208) * *$ & .534 \\
\hline POS & $.092(.481)$ & 1.096 & $.235(.602)$ & 1.265 & $.460(.488)$ & 1.584 & $.468(.472)$ & 1.597 & $-.376(.229)$ & .687 \\
\hline PSS & $.176(.347)$ & 1.192 & $-.553(.458)$ & .575 & $-.150(.357)$ & .861 & $-.128(.334)$ & .880 & $.305(.239)$ & 1.357 \\
\hline PCS & $.741(.435)$ & 2.098 & $.737(.580)$ & 2.090 & $.254(.423)$ & 1.289 & $.257(.369)$ & 1.293 & $.484(.298)$ & 1.623 \\
\hline Sex & $-.508(1.063)$ & .602 & $-.444(1.399)$ & .641 & $-.016(1.056)$ & .984 & $.400(1.116)$ & 1.492 & $-.909(.709)$ & .403 \\
\hline Age & $-.206(.291)$ & .814 & $.320(.349)$ & 1.377 & $-.099(.285)$ & .906 & $-.165(.262)$ & .848 & $-.042(.207)$ & .959 \\
\hline Profession & $-.803(.549)$ & .448 & $-.404(.711)$ & .668 & $-.764(.553)$ & .466 & $-.094(.532)$ & .910 & $-.709(.365)$ & .492 \\
\hline Public/Private & $-1.111(.516)^{*}$ & .329 & $-.961(.762)$ & .383 & $-1.034(.527)^{*}$ & .356 & $-1.084(.475)^{*}$ & .338 & $-.027(.348)$ & .973 \\
\hline Work time & $-.226(.787)$ & .798 & $-.138(.988)$ & .871 & $-.309(.778)$ & .734 & $-.206(.698)$ & .814 & $-.021(.481)$ & .979 \\
\hline \multirow[t]{3}{*}{ Tenure position } & $.866(.329)^{* *}$ & 2.377 & $.939(.376)^{*}$ & 2.557 & $.547(.349)$ & 1.728 & $.778(.322)^{*}$ & 2.177 & $.088(.166)$ & 1.092 \\
\hline & \multicolumn{2}{|c|}{ Profile 2 vs. Profile 4} & \multicolumn{2}{|c|}{ Profile 3 vs. Profile 4} & \multicolumn{2}{|c|}{ Profile 1 vs. Profile 3} & \multicolumn{2}{|c|}{ Profile 2 vs. Profile 3} & \multicolumn{2}{|c|}{ Profile 1 vs. Profile 2} \\
\hline & Coef. (SE) & OR & Coef. (SE) & OR & Coef. (SE) & OR & Coef. (SE) & OR & Coef. (SE) & OR \\
\hline PRB (S-factor) & $.090(.398)$ & 1.094 & $.059(.277)$ & 1.061 & $.280(.298)$ & 1.323 & $.031(.424)$ & 1.031 & $.249(.410)$ & 1.283 \\
\hline WRB (S-factor) & $-1.614(.406)^{* *}$ & .199 & $.171(.223)$ & 1.186 & $-.613(.252)^{*}$ & .542 & $-1.785(.427)^{* *}$ & .168 & $1.171(.431)^{*}$ & 3.225 \\
\hline PIB (S-factor) & $-.478(.789)$ & .620 & $.160(.359)$ & 1.174 & $-.274(.456)$ & .760 & $-.639(.820)$ & .528 & $.365(.861)$ & 1.441 \\
\hline GB (G-Factor) & $-1.001(.480)^{*}$ & .368 & $.518(.203)^{*}$ & 1.679 & $-1.145(.235)^{* *}$ & .318 & $-1.519(.503)^{* *}$ & .219 & $.373(.516)$ & 1.452 \\
\hline POS & $-.233(.410)$ & .792 & $-.008(.257)$ & .992 & $-.368(.275)$ & .692 & $-.225(.443)$ & .799 & $-.143(.420)$ & .867 \\
\hline PSS & $-.424(.355)$ & .654 & $-.022(.248)$ & .978 & $.326(.272)$ & 1.385 & $-.403(.385)$ & .668 & $.729(.395)$ & 2.073 \\
\hline PCS & $.480(.467)$ & 1.616 & $-.003(.298)$ & .997 & $.487(.348)$ & 1.627 & $.483(.511)$ & 1.621 & $.004(.490)$ & 1.004 \\
\hline Sex & $-.845(.908)$ & .430 & $-.416(.689)$ & .660 & $-.492(.697)$ & .611 & $-.428(.941)$ & .652 & $-.064(.950)$ & .938 \\
\hline Age & $.485(.269)$ & 1.624 & $.066(.211)$ & 1.068 & $-.107(.231)$ & .899 & $.420(.297)$ & 1.522 & $-.527(.292)$ & .590 \\
\hline Profession & $-.310(.556)$ & .733 & $-.670(.385)$ & .512 & $-.039(.378)$ & .962 & $.360(.584)$ & 1.433 & $-.399(.570)$ & .671 \\
\hline Public/Private & $.122(.632)$ & 1.130 & $.049(.383)$ & 1.050 & $-.076(.397)$ & .927 & $.073(.677)$ & 1.076 & $-.149(.635)$ & .862 \\
\hline Work time & $.067(.707)$ & 1.069 & $-.103(.543)$ & .902 & $.083(.556)$ & 1.087 & $.171(.789)$ & 1.186 & $-.088(.766)$ & .916 \\
\hline Tenure position & $.161(.232)$ & 1.175 & $-.231(.236)$ & .794 & $.320(.236)$ & 1.377 & $.392(.294)$ & 1.480 & $-.073(.249)$ & .930 \\
\hline
\end{tabular}

Note. $* p<.05 ; * * p<.01$; SE: Standard Error of the coefficient; OR: Odds Ratio; PRB: Person-Related Bullying; WRB: Work-Related Bullying; PIB: Physically-

Intimidating Bullying; GB: Global Bullying; POS: Perceived Organizational Support; PSS: Perceived Supervisor Support; PCS: Perceived Colleagues Support; S-factor:

Specific factor score from preliminary bifactor measurement models; G-factor: Global factor score from preliminary bifactor measurement models; indicators of PRB, WRB, PIB, GB, POS, PSS, and PCS are estimated from factor scores with a mean of 0 and a standard deviation of 1 in the total sample; age and tenure have been standardized prior to the analyses; sex: 0 male and 1 female; work time: 0 full time and 1 part time; the coefficients and OR reflects the effects of the predictors on the likelihood of membership into the first listed profile relative to the second listed profile; Profile 1: Moderately High Ability to Achieve Recovery; Profile 2: High Ability to Achieve Recovery; Profile 3: Moderately Low Ability to Achieve Recovery; Profile 4: Normative; Profile 5: Low Ability to Achieve Recovery. 


\section{Table 4}

Associations between Profile Membership and the Outcomes (Study 1)

\begin{tabular}{|c|c|c|c|c|c|}
\hline & $\begin{array}{c}\text { Profile } 1 \\
\mathrm{M}[\mathrm{CI}] \\
\end{array}$ & $\begin{array}{c}\text { Profile } 2 \\
\mathrm{M}[\mathrm{CI}] \\
\end{array}$ & $\begin{array}{c}\text { Profile } 3 \\
\mathrm{M}[\mathrm{CI}] \\
\end{array}$ & $\begin{array}{c}\text { Profile } 4 \\
\mathrm{M}[\mathrm{CI}] \\
\end{array}$ & $\begin{array}{c}\text { Summary of Statistically } \\
\text { Significant Differences }\end{array}$ \\
\hline Burnout & $-.167[-.292 ;-.042]$ & $.878[.613 ; 1.143]$ & $.200[.065 ; .335]$ & $-.845[-1.139 ;-.551]$ & $4<1<3<2$ \\
\hline Sleeping Difficulties & $-.240[-.362 ;-.118]$ & $.902[.682 ; 1.122]$ & $.172[.019 ; .325]$ & $-.459[-.761 ;-.157]$ & $1=4<3<2$ \\
\hline $\begin{array}{l}\text { Counterproductive Work } \\
\text { Behaviors }\end{array}$ & $-.021[-.135 ; .093]$ & $.195[-.003 ; .393]$ & $.091[-.056 ; .238]$ & $-.030[-.297 ; .237]$ & $1=2=3=4$ \\
\hline Job Satisfaction & $2.961[2.863 ; 3.059]$ & $2.468[2.247 ; 2.689]$ & $2.807[2.687 ; 2.927]$ & $3.068[2.860 ; 3.276]$ & $2<3<4 ; 2<1 ; 1=3 ; 1=4$ \\
\hline Absenteeism & $9.144[3.713 ; 14.575]$ & $19.117[-1.265 ; 39.499]$ & $7.762[2.944 ; 12.580]$ & $7.000[-1.112 ; 15.112]$ & $1=2=3=4$ \\
\hline Job Performance & $7.189[6.924 ; 7.454]$ & $6.551[5.992 ; 7.110]$ & $6.993[6.732 ; 7.254]$ & $7.808[7.424 ; 8.192]$ & $2<1<4 ; 3<4 ; 1=3 ; 2=3$ \\
\hline
\end{tabular}

Note. M: Mean; CI: 95\% Confidence Interval; indicators of burnout, sleeping difficulties, and counterproductive work behaviors are estimated from factor scores with a mean of 0 and a standard deviation of 1 in the total sample; Profile 1: Moderately High Ability to Achieve Recovery; Profile 2: Low Ability to Achieve Recovery; Profile 3:

Moderately Low Ability to Achieve Recovery; Profile 4: High Ability to Achieve Recovery.

\section{Table 5}

Associations between Profile Membership and the Outcomes (Study 2)

\begin{tabular}{|c|c|c|c|c|c|c|}
\hline & $\begin{array}{c}\text { Profile } 1 \\
\text { M [CI] }\end{array}$ & $\begin{array}{c}\text { Profile } 2 \\
\text { M [CI] }\end{array}$ & $\begin{array}{c}\text { Profile } 3 \\
\text { M [CI] }\end{array}$ & $\begin{array}{c}\text { Profile } 4 \\
\mathrm{M}[\mathrm{CI}]\end{array}$ & $\begin{array}{c}\text { Profile } 5 \\
\mathrm{M}[\mathrm{CI}]\end{array}$ & $\begin{array}{c}\text { Summary of } \\
\text { Statistically Significant } \\
\text { Differences }\end{array}$ \\
\hline Burnout & $-.393[-.550 ;-.236]$ & $-1.026[-1.402 ;-.650]$ & $.474[.260 ; .688]$ & .024 [-.101; .149] & $.888[.569 ; 1.207]$ & $2<1<4<3<5$ \\
\hline Sleeping Difficulties & $-.306[-.469 ;-.143]$ & $-.826[-1.185 ;-.467]$ & $.496[.282 ; .710]$ & $.006[-.119 ; .131]$ & $.585[.307 ; .863]$ & $2<1<4<3=5$ \\
\hline Job Satisfaction & $2.969[2.867 ; 3.071]$ & $3.079[2.895 ; 3.263]$ & $2.604[2.459 ; 2.749]$ & $2.574[2.464 ; 2.684]$ & $2.279[2.071 ; 2.487]$ & $5<3=4<1=2$ \\
\hline Job Performance & $7.191[6.911 ; 7.471]$ & 7.909 [7.397; 8.421] & $6.507[6.103 ; 6.911]$ & $6.827[6.570 ; 7.084]$ & $6.170[5.535 ; 6.805]$ & $\begin{array}{c}3=5<1<2 ; 1=4 \\
3=4 ; 5<4<2\end{array}$ \\
\hline
\end{tabular}

Note. M: Mean; CI: 95\% Confidence Interval; indicators of burnout and sleeping difficulties are estimated from factor scores with a mean of 0 and a standard deviation of 1 in the total sample. Profile 1: Moderately High Ability to Achieve Recovery; Profile 2: High Ability to Achieve Recovery; Profile 3: Moderately Low Ability to Achieve Recovery; Profile 4: Normative; Profile 5: Low Ability to Achieve Recovery. 


\section{Online Supplemental Materials for:}

\section{A Person-Centered Perspective on the Factors Associated with the Work Recovery Process}

\section{Authors' note:}

These online technical appendices are to be posted on the journal website and hot-linked to the manuscript. If the journal does not offer this possibility, these materials can alternatively be posted on one of our personal websites (we will adjust the in-text reference upon acceptance).

We would also be happy to have some of these materials brought back into the main manuscript, or included as published appendices if you deem it useful. We developed these materials to provide additional technical information and to keep the main manuscript from becoming needlessly long. 


\section{Table S1}

Number and Characteristics of Profiles in Prior Research

\begin{tabular}{|c|c|c|c|c|c|}
\hline Study & Sample & Analysis & Indicators & Profiles & Covariates \\
\hline $\begin{array}{l}\text { Siltaloppi et al. } \\
\text { (2012) }\end{array}$ & $\begin{array}{l}\text { 274 Finnish } \\
\text { employees. } \\
\text { Variety of } \\
\text { sectors }\end{array}$ & $\begin{array}{l}\text { Latent } \\
\text { Profile } \\
\text { Analysis }\end{array}$ & $\begin{array}{l}\text { Need for recovery. } \\
\text { Measured two times } \\
\text { (2007 and 2008) }\end{array}$ & $\begin{array}{l}\text { Profile } 1 \text {. Low need for recovery (Stable low need } \\
\text { for recovery over time) } \\
\text { Profile } 2 \text {. Moderately low need for recovery (Stable } \\
\text { moderately low need for recovery over time) } \\
\text { Profile } 3 \text {. Average need for recovery (Stable average } \\
\text { need for recovery over time) } \\
\text { Profile } 4 \text {. Moderately high need for recovery (Stable } \\
\text { moderately high need for recovery over time) } \\
\text { Profile 5. High need for recovery (Stable high need } \\
\text { for recovery over time) }\end{array}$ & $\begin{array}{l}\text { Time demands at work: } 1,2<3,5 \\
\text { Job control: } 1,2>5 \\
\text { Support of the supervisor: } 1,2>5 \\
\text { Justice of the supervisor: } 1,2>4,5 ; 3>5 \\
\text { Psychological detachment: } 1,3>4,5 ; 2>3 \\
\text { Relaxation: } 1,2>3,5 ; 3>4,5 \\
\text { Mastery: No differences } \\
\text { Control: } 1,3>4,5 ; 1>3\end{array}$ \\
\hline Feldt et al. (2013) & $\begin{array}{l}298 \text { Finnish } \\
\text { managers }\end{array}$ & $\begin{array}{l}\text { Latent } \\
\text { Profile } \\
\text { Analysis }\end{array}$ & $\begin{array}{l}\text { Effort-Reward } \\
\text { imbalance and } \\
\text { overcommitment. } \\
\text { Measured three } \\
\text { times }(2006,2008 \text {, } \\
\text { and 2010) }\end{array}$ & $\begin{array}{l}\text { Profile } 1 . \text { No imbalance between effort and reward, } \\
\text { and moderate levels of overcommitment } \\
\text { Profile } 2 . \text { No imbalance between effort and reward, } \\
\text { and low levels of overcommitment } \\
\text { Profile } 3 \text {. High imbalance between effort and } \\
\text { reward, and high levels of overcommitment } \\
\text { Profile } 4 \text {. High imbalance between effort and } \\
\text { reward, and moderate levels of overcommitment } \\
\text { (both decreasing over time) } \\
\text { Profile 5. High imbalance between effort and reward } \\
\text { (increasing over time), and high levels of } \\
\text { overcommitment (curvilinear) }\end{array}$ & $\begin{array}{l}\text { Time } 1 \text { burnout: } 1,2<3 \\
\text { Time } 2 \text { burnout: } 1,2,4<3 ; 5>3 \\
\text { Time } 3 \text { burnout: } 1,2,4<3 ; 5>3 \\
\text { Time } 1 \text { work engagement: } 4<3 \\
\text { Time } 2 \text { work engagement: } 4,5<3 \\
\text { Time } 3 \text { work engagement: } 5<3 \\
\text { Time } 3 \text { psychological detachment: } 2>1,3,5 ; 3<1 \text {, } \\
2,4 \\
\text { Time } 3 \text { relaxation: } 2>1,3,5 ; 3<1,2,4 \\
\text { Time } 3 \text { control: } 2>1,3,4,5 \\
\text { Time } 3 \text { mastery: No differences }\end{array}$ \\
\hline $\begin{array}{l}\text { Kinnunen et al. } \\
\text { (2015) }\end{array}$ & $\begin{array}{l}1122 \text { Finnish } \\
\text { employees }\end{array}$ & $\begin{array}{l}\text { Latent } \\
\text { Profile } \\
\text { Analysis }\end{array}$ & $\begin{array}{l}\text { Work-related, } \\
\text { private, and } \\
\text { physical energy } \\
\text { management } \\
\text { strategies }\end{array}$ & $\begin{array}{l}\text { Profile 1. Passives (low levels of energy } \\
\text { management strategies) } \\
\text { Profile 2. Averages (moderate levels of energy } \\
\text { management strategies) } \\
\text { Profile 3. Casuals (moderately high levels of energy } \\
\text { management strategies) } \\
\text { Profile 4. Actives (moderately high levels of private } \\
\text { energy management strategies, and high levels of } \\
\text { work-related and physical energy management } \\
\text { strategies) }\end{array}$ & $\begin{array}{l}\text { Job exhaustion: } 1>3 \\
\text { Vigor at work: } 3,4>1,2 \\
\text { Vitality: } 4>3>1,2 \\
\text { Workload: No differences } \\
\text { Cognitive demands: No differences } \\
\text { Job variety: No differences } \\
\text { Job autonomy: } 2,3>1 \\
\text { Colleague support: } 4>1,2 ; 3>1 \\
\text { Supervisor support: } 4>1,2 ; 3>1\end{array}$ \\
\hline
\end{tabular}




\begin{tabular}{|c|c|c|c|c|c|}
\hline Study & Sample & Analysis & Indicators & Profiles & Covariates \\
\hline $\begin{array}{l}\text { Bennett et al. (2016). } \\
\text { Study } 1\end{array}$ & $\begin{array}{l}575 \text { US } \\
\text { employees } \\
\text { (MTurk) }\end{array}$ & $\begin{array}{l}\text { Latent } \\
\text { Profile } \\
\text { Analysis }\end{array}$ & $\begin{array}{l}\text { Relaxation; } \\
\text { mastery; control; } \\
\text { problem-solving } \\
\text { pondering; and } \\
\text { psychological } \\
\text { detachment. }\end{array}$ & $\begin{array}{l}\text { Profile 1. Recovering ponderers (High levels of } \\
\text { relaxation, mastery, control, and problem-solving } \\
\text { pondering, and moderately high levels of } \\
\text { psychological detachment) } \\
\text { Profile 2. Leaving work behind (High levels of } \\
\text { psychological detachment, relaxation, mastery, and } \\
\text { control, and the lowest levels of problem-solving } \\
\text { pondering } \\
\text { Profile 3. Pondering (Highest levels of problem- } \\
\text { solving pondering, moderate levels of mastery and } \\
\text { control, low levels of relaxation, and the lowest } \\
\text { levels of psychological detachment) } \\
\text { Profile } 4 \text {. Detach, low relax (High levels of } \\
\text { psychological detachment, and lower levels of } \\
\text { relaxation, mastery, control, and problem-solving } \\
\text { pondering) }\end{array}$ & $\begin{array}{l}\text { Role ambiguity: } 3>2 \\
\text { Time pressure: } 4<1,2,3 \\
\text { Job control: } 1,2,4<3 ; 1>2 \\
\text { Emotional exhaustion: } 1>4 ; 2<1,3,4 \\
\text { Engagement: } 4<1,3 ; 3>1>2,4 \\
\text { Somatic complaints: } 4>2 ; 3>1>2\end{array}$ \\
\hline $\begin{array}{l}\text { Bennett et al. (2016). } \\
\text { Study } 2\end{array}$ & $\begin{array}{l}401 \text { US } \\
\text { University } \\
\text { employees }\end{array}$ & $\begin{array}{l}\text { Latent } \\
\text { Profile } \\
\text { Analysis }\end{array}$ & $\begin{array}{l}\text { Relaxation; } \\
\text { mastery; control; } \\
\text { problem-solving } \\
\text { pondering; and } \\
\text { psychological } \\
\text { detachment. } \\
\text { Outcomes measured } \\
\text { at two time points } \\
(2 \text { weeks) }\end{array}$ & $\begin{array}{l}\text { Profile 1. Recovering ponderers (Moderate to high } \\
\text { levels of relaxation, mastery, control, and problem- } \\
\text { solving pondering, and low levels of psychological } \\
\text { detachment) } \\
\text { Profile 2. Leaving work behind (Moderate to high } \\
\text { levels of psychological detachment, relaxation, } \\
\text { mastery, and control, and the lowest levels of } \\
\text { problem-solving pondering) } \\
\text { Profile 3. Pondering (High levels of problem-solving } \\
\text { pondering, moderate levels of mastery, and low } \\
\text { levels of control, relaxation, and psychological } \\
\text { detachment) }\end{array}$ & $\begin{array}{l}\text { Role ambiguity: } 1,3>2 \\
\text { Time pressure: } 1,3>2 \\
\text { Job control: } 1,3>2 \\
\text { Supervisor support for recovery: } 1,3<2 \\
\text { Leader-member exchange: } 3>2 \\
\text { Time } 1 \text { emotional exhaustion: } 3>1>2 \\
\text { Time } 1 \text { engagement: } 1>3>2 \\
\text { Time } 1 \text { somatic complaints: } 3>1,2 \\
\text { Time } 2 \text { emotional exhaustion: } 1,3>2 \\
\text { Time } 2 \text { engagement: } 1>3>2 \\
\text { Time } 2 \text { somatic complaints: } 3>1,2\end{array}$ \\
\hline
\end{tabular}




\begin{tabular}{|c|c|c|c|c|c|}
\hline Study & Sample & Analysis & Indicators & Profiles & Covariates \\
\hline $\begin{array}{l}\text { Kinnunen et al. } \\
\text { (2016) }\end{array}$ & $\begin{array}{l}1106 \text { Finnish } \\
\text { employees. } \\
\text { Variety of } \\
\text { sectors }\end{array}$ & $\begin{array}{l}\text { Latent } \\
\text { Profile } \\
\text { Analysis }\end{array}$ & $\begin{array}{l}\text { Nonwork } \\
\text { interrupting work } \\
\text { behaviors and work } \\
\text { interrupting } \\
\text { nonwork behaviors. }\end{array}$ & $\begin{array}{l}\text { Profile 1. Work guardians (High levels of work } \\
\text { interrupting nonwork behaviors and low levels on } \\
\text { nonwork interrupting work behaviors) } \\
\text { Profile 2. Nonwork guardians (Low levels of work } \\
\text { interrupting nonwork behaviors and high levels of } \\
\text { nonwork interrupting work behaviors) } \\
\text { Profile 3. Integrators (High levels of both nonwork } \\
\text { interrupting work behaviors and work interrupting } \\
\text { nonwork behaviors) } \\
\text { Profile 4. Separators (Low levels of both nonwork } \\
\text { interrupting work behaviors and work interrupting } \\
\text { nonwork behaviors) } \\
\text { Profile 5. Intermediate (Average levels of both } \\
\text { nonwork interrupting work behaviors and work } \\
\text { interrupting nonwork behaviors) }\end{array}$ & $\begin{array}{l}\text { Psychological detachment: } 1,3<2,4,5 ; 5<4 \\
\text { Relaxation: } 1<2,3,4,5 ; 3,5<4 \\
\text { Mastery: No differences } \\
\text { Control: } 1<2,3,4,5 ; 3<4 \\
\text { Job exhaustion: } 1>2,5 \\
\text { Vigor at work: No differences }\end{array}$ \\
\hline Huhtala et al. (2017) & $\begin{array}{l}133 \text { Finnish } \\
\text { school } \\
\text { psychologists }\end{array}$ & $\begin{array}{l}\text { Latent } \\
\text { Profile } \\
\text { Analysis }\end{array}$ & $\begin{array}{l}\text { Cross-role boundary } \\
\text { interruption: Ethical } \\
\text { dilemma; ethical } \\
\text { rumination; and } \\
\text { ethical stress. }\end{array}$ & $\begin{array}{l}\text { Profile 1. High ruminators (High levels of ethical } \\
\text { rumination frequency and ethical dilemma } \\
\text { frequency, and average levels of ethical stress } \\
\text { intensity) } \\
\text { Profile 2. Intermediate (Average levels of ethical } \\
\text { rumination frequency, ethical stress intensity, and } \\
\text { ethical dilemma frequency) } \\
\text { Profile 3. Low ruminators (Low levels of ethical } \\
\text { rumination frequency and ethical stress intensity, } \\
\text { and moderate levels of ethical dilemma frequency) }\end{array}$ & $\begin{array}{l}\text { Exhaustion: } 1>3 \\
\text { Vigor: } 3,2>1 \\
\text { Sleeping problems: } 1>2,3\end{array}$ \\
\hline $\begin{array}{l}\text { Kinnunen et al. } \\
\text { (2017a) }\end{array}$ & $\begin{array}{l}841 \text { Finnish } \\
\text { employees. } \\
\text { Variety of } \\
\text { sectors }\end{array}$ & $\begin{array}{l}\text { Latent } \\
\text { Profile } \\
\text { Analysis }\end{array}$ & $\begin{array}{l}\text { Boundary crossing } \\
\text { from work to } \\
\text { nonwork. } \\
\text { Measured two times } \\
\text { (2013 and 2014) }\end{array}$ & $\begin{array}{l}\text { Profile } 1 \text {. Slightly increasing boundary crossing } \\
\text { behavior over time } \\
\text { Profile } 2 \text {. Boundary crossing behavior decreased } \\
\text { over time from moderate to low } \\
\text { Profile } 3 \text {. Stable moderate boundary crossing } \\
\text { behavior over time } \\
\text { Profile } 4 \text {. Increase in boundary crossing behavior } \\
\text { from relatively low to moderate } \\
\text { Profile } 5 \text {. Stable low boundary crossing behavior } \\
\text { over time } \\
\text { Profile } 6 \text {. Stable high boundary crossing behavior } \\
\text { over time }\end{array}$ & $\begin{array}{l}\text { Time } 1 \text { detachment: } 6<1-5 ; 3<1,5 \\
\text { Time } 1 \text { affective rumination: No differences } \\
\text { Time } 1 \text { problem-solving pondering: } 6>1-5 ; 5<1- \\
4,6 ; 3>1,4,5 \\
\text { Time } 2 \text { detachment: } 6<1-5 ; 3<1,2,5 ; 1>4 \\
\text { Time } 2 \text { affective rumination: No differences } \\
\text { Time } 2 \text { problem-solving pondering: } 6>1-5 ; 5<1 \text {, } \\
3,4,6 ; 3>1,2,5\end{array}$ \\
\hline
\end{tabular}




\begin{tabular}{|c|c|c|c|c|c|}
\hline Study & Sample & Analysis & Indicators & Profiles & Covariates \\
\hline $\begin{array}{l}\text { Kinnunen et al. } \\
\text { (2017b) }\end{array}$ & $\begin{array}{l}664 \text { Finnish } \\
\text { employees. } \\
\text { Variety of } \\
\text { sectors }\end{array}$ & $\begin{array}{l}\text { Latent } \\
\text { Profile } \\
\text { Analysis }\end{array}$ & $\begin{array}{l}\text { Rumination; } \\
\text { problem-solving } \\
\text { pondering; and } \\
\text { psychological } \\
\text { detachment. } \\
\text { Measured three } \\
\text { times }(2013,2014 \text {, } \\
\text { and 2015) }\end{array}$ & $\begin{array}{l}\text { Profile 1. No rumination (Low levels of rumination } \\
\text { and problem-solving pondering, and high levels of } \\
\text { psychological detachment) } \\
\text { Profile 2. Moderate detachment from work } \\
\text { (Relatively low levels of rumination and problem- } \\
\text { solving pondering, and average levels of } \\
\text { psychological detachment) } \\
\text { Profile 3. Moderate work-related rumination with } \\
\text { low psychological detachment (Average levels of } \\
\text { rumination and problem-solving pondering, and low } \\
\text { levels of psychological detachment) } \\
\text { Profile } 4 \text {. High affective rumination combined with } \\
\text { low psychological detachment (High levels of } \\
\text { rumination, moderately low levels of problem- } \\
\text { solving pondering, and low levels of psychological } \\
\text { detachment) } \\
\text { Profile 5. High problem-solving pondering combined } \\
\text { with low psychological detachment (High levels of } \\
\text { problem-solving pondering, and low levels of } \\
\text { rumination and psychological detachment) }\end{array}$ & $\begin{array}{l}\text { Time pressure: } 1,2<3,4,5 \\
\text { Cognitive demands: } 1,2<3,5 ; 1<4 \\
\text { Emotional demands: } 1,2<3,4,5 ; 1<2 \\
\text { Job exhaustion: } 1,2,5<3,4 ; 1<2 ; 3<4 \\
\text { Sleeping problems: } 1,2,5<3,4 ; 1<2,5 ; 2<5 \\
\text { Work engagement: } 4<1,2,3,5 ; 2,3<5 ; 3<2 \\
\end{array}$ \\
\hline Perko et al. (2017) & $\begin{array}{l}625 \text { Finnish } \\
\text { municipal } \\
\text { employees }\end{array}$ & $\begin{array}{l}\text { Factor } \\
\text { Mixture } \\
\text { Analyses }\end{array}$ & $\begin{array}{l}\text { Rumination. } \\
\text { Measured three } \\
\text { times (T1 in } 2011 \text {, } \\
\text { T2 } 14 \text { months later, } \\
\text { and T3 } 8 \text { months } \\
\text { later) }\end{array}$ & $\begin{array}{l}\text { Profile 1. Low (Stable low rumination over time) } \\
\text { rumination over time) } \\
\text { Profile } 3 \text {. Decreasing (High to low levels of } \\
\text { rumination over time) } \\
\text { Profile } 4 \text {. High (Stable high rumination over time) } \\
\text { Profile 5. Moderate (Stable moderate rumination } \\
\text { over time) }\end{array}$ & $\begin{array}{l}\text { Time } 1 \text { workload: } 1<3,4,5 ; 2,5<4 \\
\text { Time } 1 \text { cognitive demands: } 1<4,5 \\
\text { Time } 1 \text { emotional demands: } 1<3,4,5 ; 4>2,3,5 \\
\text { Time } 1 \text { transformational leadership: } 1>4,5 \\
\text { Time } 1 \text { supervisor fairness: } 1>4,5 ; 4<3,5 \\
\text { Time } 1 \text { conflict management: } 1>4,5 ; 3>4,5 \\
\text { Time } 1 \text { abusive supervision: } 1<4,5 ; 3<4,5 \\
\text { Time } 3 \text { workload: } 1<4,5 \\
\text { Time } 3 \text { cognitive demands: } 1,3<4,5 \\
\text { Time } 3 \text { emotional demands: } 1<4,5 ; 3<5 ; 4>2,3 \\
\text { Time } 3 \text { transformational leadership: No differences } \\
\text { Time } 3 \text { supervisor fairness: } 1>4 \\
\text { Time } 3 \text { conflict management: No differences } \\
\text { Time } 3 \text { abusive supervision: } 1<5 \\
\text { Time } 1 \text { exhaustion: } 1,2<3,4,5 ; 3,5<4 \\
\text { Time } 3 \text { exhaustion: } 1<2,4,5 ; 3<2,4,5 ; 4<5\end{array}$ \\
\hline
\end{tabular}




\begin{tabular}{|c|c|c|c|c|c|}
\hline Study & Sample & Analysis & Indicators & Profiles & Covariates \\
\hline Chawla et al. (2020) & $\begin{array}{l}207 \text { full-time } \\
\text { employees in } \\
\text { the United } \\
\text { States }\end{array}$ & $\begin{array}{l}\text { Multilevel } \\
\text { Latent } \\
\text { Profile } \\
\text { Analysis }\end{array}$ & $\begin{array}{l}\text { Psychological } \\
\text { detachment; } \\
\text { relaxation; mastery; } \\
\text { and control. } \\
\text { Measured twice a } \\
\text { day for five } \\
\text { consecutive } \\
\text { working days }\end{array}$ & $\begin{array}{l}\text { Profile 1. Plugged In (low levels of psychological } \\
\text { detachment, relaxation, mastery, and control) } \\
\text { Profile 2. Controlled Non-Mastery Recovering } \\
\text { (moderate levels of control, psychological } \\
\text { detachment, and relaxation, and very low levels of } \\
\text { mastery) } \\
\text { Profile 3. Moderately Unplugged (moderate levels of } \\
\text { psychological detachment, relaxation, mastery, and } \\
\text { control) } \\
\text { Profile 4. Non-Mastery Recovering (high levels of } \\
\text { psychological detachment, relaxation, and control, } \\
\text { and low levels of mastery) } \\
\text { Profile 5. Unplugged (high levels of psychological } \\
\text { detachment, relaxation, mastery, and control) }\end{array}$ & $\begin{array}{l}\text { Role ambiguity: } 1,2,3,4>5 ; 2>4 \\
\text { Time pressure: } 1>4,5 ; 2,3>4 \\
\text { Social support: No differences } \\
\text { Next-day morning sleep quality: } 1<2,3,4,5 ; 2<4 \text {, } \\
5 ; 3<4 \text {; } \\
\text { Next-day morning emotional exhaustion: } 1>2,3,4 \text {, } \\
5 ; 2>4,5 \text {; } \\
\text { Next-day afternoon emotional exhaustion: } 1>2,3,4 \\
>5 \\
\text { Next-day afternoon engagement: } 1,2,4<3,5 \\
\text { Next-day afternoon helping behavior: } 1,2,4<5 ; 3> \\
4 \\
\text { Next-day afternoon personal initiative: } 1,2,4<5 ; 3 \\
>4\end{array}$ \\
\hline
\end{tabular}




\section{References}

Bennett, A., Gabriel, A., Calderwood, C., Dahling, J., \& Trougakos, J. (2016). Better together? Examining profiles of employee recovery experiences. Journal of Applied Psychology, 101, 1635-1654.

Chawla, N., MacGowan, R.L., Gabriel, A.S., \& Podsakoff, N.P. (2020). Unplugging or staying connected? Examining the nature, antecedents, and consequences of profiles of daily recovery experiences. Journal of Applied Psychology, 105, 19-39.

Feldt, T., Huhtala, M., Kinnunen, U., Hyvönen, K., Mäkikangas, A., \& Sonnentag, S. (2013). Longterm patterns of effort-reward imbalance and over-commitment: Investigating occupational well-being and recovery experiences as outcomes. Work \& Stress, 27, 64-87.

Huhtala, M., Kinnunen, U., \& Feldt, T. (2017). School psychologists' ethical strain and rumination: Individual profiles and associations with weekly well-being. Psychology in the Schools, 54, 127-141.

Kinnunen, U., Feldt, T., de Bloom, J., \& Korpela, K. (2015). Patterns of daily energy management at work: Relations to employee well-being and job characteristics. International Archives of Occupational and Environmental Health, 88, 1077-1086.

Kinnunen, U., Feldt, T., de Bloom, J., Sianoja, M., Korpela, K., \& Geurts, S. (2017a). Linking boundary crossing from work to nonwork to work-related rumination across time: A variableand person-oriented approach. Journal of Occupational Health Psychology, 22, 467-480.

Kinnunen, U., Feldt, T., Sianoja, M., de Bloom, J., Korpela, K., \& Geurts, S. (2017b). Identifying long-term patterns of work-related rumination: Associations with job demands and well-being outcomes. European Journal of Work and Organizational Psychology, 26, 514-526.

Kinnunen, U., Rantanen, J., de Bloom, J., Mauno, S., Feldt, T., \& Korpela, K. (2016). The role of work-nonwork boundary management in work stress recovery. International Journal of Stress Management, 23, 99-123.

Perko, K., Kinnunen, U., \& Feldt, T. (2017). Long-term profiles of work-related rumination associated with leadership, job demands, and exhaustion: A three-wave study. Work \& Stress, 31, 395-420.

Siltaloppi, M., Kinnunen, U., Feldt, T., \& Tolvanen, A. (2012). Development of need for recovery from work over one year: A person-centered approach. Anxiety, Stress \& Coping: An International Journal, 25, 23-42. 


\section{Preliminary Measurement Models}

Due to the complexity of the multi-sample measurement models underlying all constructs assessed in the present research, preliminary analyses were conducted separately for the profile variables, and for the predictor and outcome variables. These analyses were all conducted using Mplus 8 (Muthén \& Muthén, 2017) robust weight least square estimator (WLSMV) to account for the ordered-categorical nature of the Likert scales used in this study (Finney \& DiStefano, 2013). A limitation of WLSMV, when compared to Maximum Likelihood, is a slightly less efficient way of handling missing data (Asparouhov \& Muthén, 2010), which is not an issue here given the low level of missing data at the item level (i.e., 0 to $1.0 \%$ in Study $1 ; 0$ to $0.5 \%$ in Study 2).

For the profile indictors, a three-factor confirmatory factor analysis (CFA) representation of participants' overcommitment, psychological detachment, and rumination was estimated in Study 1. Each item was only allowed to load on the factor it was assumed to measure, no cross-loadings were allowed, and all factors were allowed to freely correlate. In Study 2, a similar CFA model was used, but including four factors reflecting participants' overcommitment, psychological detachment, rumination, and need for recovery was estimated. In these two models, in order to achieve the local identification of the rumination factors (including only two indicators), essentially tau-equivalent constraints (ETEC) were incorporated to the model (i.e., both factor loadings were constrained to equality; Little et al., 1999). To ascertain the distinctiveness of the factors, alternative models were estimated for both studies in which factors were combined in pairs.

For the predictors and outcomes, a CFA measurement model included eight correlated factors related to perceived organizational support, perceived supervisor support, perceived colleagues support, workload, emotional dissonance, emotional exhaustion, sleeping difficulties, and counterproductive work behaviors was estimated for Study 1. In Study 2, the model with the predictors and outcomes included five correlated factors representing perceived organizational support, perceived supervisor support, perceived colleagues support, emotional exhaustion, and sleeping difficulties. This model also included a bifactor (Morin et al., 2020) representation of bullying encompassing one global bullying factor (G-factor) and three orthogonal specific factors estimated from the same items and reflecting specific levels (S-factors) of person-related bullying (S-factor), work-related bullying (S-factor), and physically intimidating bullying (S-factor) left unexplained by the G-factor. An orthogonal method factor was used to control for the methodological artefact associated with the negative wording of six items from the support scales, and a priori correlated uniquenesses were also integrated to control for the parallel wording of the support items across sources (Marsh et al., 2010).

For both models, we report standardized parameter estimates and composite reliability coefficients calculated using McDonald (1970) omega (Morin et al., 2020):

$$
\omega=\frac{\left(\sum\left|\lambda_{i}\right|\right)^{2}}{\left[\left(\sum\left|\lambda_{i}\right|\right)^{2}+\sum \delta_{i}\right]}
$$

where $\left|\lambda_{i}\right|$ are the standardized factor loadings in absolute values, and $\delta i$, the item uniquenesses.

In order to ensure measurement stability across studies, we finally conducted tests of measurement invariance across samples for the variables common to both studies (profile indicators: Overcommitment, psychological detachment, and rumination; predictors and outcomes: Perceived organizational, supervisor, and colleagues support, emotional exhaustion, sleeping difficulties, job satisfaction, and job performance). These tests were conducted in the following sequence (Millsap, 2011): (a) configural invariance (same model); (b) weak invariance (same factor loadings); (c) strong invariance (same factor loadings and response thresholds); and (d) strict invariance (same factor loadings, response thresholds, and item uniquenesses). For the profile indicators, the aformentionned ETEC (used to achieve the local identification of the rumination factor) were integrated between the weak and strong invariance steps in order to allow us to conduct proper tests of weak invariance.

Given the oversensitivity of the chi-square test of exact fit to sample size and minor misspecifications (Marsh et al., 2005), we relied on goodness-of-fit indices to describe the fit of the models: The comparative fit index (CFI), the Tucker-Lewis index (TLI), and the root mean square error of approximation (RMSEA). According to typical interpretation guidelines (e.g., Hu \& Bentler, 1999; Marsh et al., 2005; Yu, 2002), values greater than .90 and .95 for the CFI and TLI respectively are considered to be indicative of adequate and excellent fit to the data, while values smaller than .08 or .06 for the RMSEA respectively support acceptable and excellent model fit. In tests of measurement invariance, decreases in CFI and TLI greater than or equal to .01, and increases in RMSEA values 
greater than or equal to .015 between a model and the previous one in the sequence were taken to indicate a lack of measurement invariance (Chen, 2007; Cheung \& Rensvold, 2002).

Table S2 presents the goodness-of-fit indices of the measurement model estimated in both studies. In both studies, all a priori factor solutions achieved an excellent fit to the data according to all goodness-of-fit indices. In both studies, none of the alternative models (in which factors involved in the work recovery process were combined in pairs) resulted in a level of fit that was comparable to that of the a priori models, thus supporting the distinctiveness of the profile indicators considered in this research $(\Delta \mathrm{CFI}=-.024$ to $-.201 ; \Delta \mathrm{TLI}=-.028$ to $-.239 ; \Delta \mathrm{RMSEA}=+.015$ to +.080$)$. Likewise, tests of measurement invariance conducted on the measures used in both studies supported the configural, weak, strong, and strict invariance of our measurement models.

Parameter estimates are reported in Table S3 (loadings and uniquenesses) and S4 (latent correlations) for the recovery variable and in Tables S5 to S8 for the predictors and outcomes. Factor scores (with $M=0$ and $\mathrm{SD}=1$ in the each sample) for the person-centered analyses were thus extracted from these CFA solutions.

Asparouhov, T., \& Muthén, B. (2010). Weighted least square estimation with missing data. www.statmodel.com/download/GstrucMissingRevision.pdf

Chen, F F. (2007). Sensitivity of goodness of fit indexes to lack of measurement. Structural Equation Modeling, 14, 464-504.

Cheung, G.W., \& Rensvold, R.B. (2002). Evaluating goodness-of fit indexes for testing measurement invariance. Structural Equation Modeling, 9, 233-255.

Finney, S.J., \& DiStefano, C. (2013). Non-normal and categorical data in structural equation modeling. In G.R. Hancock \& R.O. Mueller (Eds), Structural equation modeling: A second course ( $2^{\text {nd }}$ ed., pp. 439-492). Greenwich, CO: IAP.

Hu, L., \& Bentler, P.M. (1999). Cutoff criteria for fit indexes in covariance structure analysis. Structural Equation Modeling, 6, 1-55. doi: 10.1080/10705519909540118

Little, T.D., Lindenberger, U., \& Nesselroade, J.R. (1999). On selecting indicators for multivariate measurement and modeling with latent variables: When "good" indicators are bad and "bad" indicators are good. Psychological Methods, 4, 192-211.

Marsh, H.W., Hau, K.-T., \& Grayson, D. (2005). Goodness of fit evaluation in structural equation modeling. In A. Maydeu-Olivares \& J. McArdle (Eds.), Contemporary psychometrics. A Festschrift for Roderick P. McDonald. Mahwah, NJ: Erlbaum.

Marsh, H.W., Scalas, L.F., \& Nagengast, B. (2010). Longitudinal tests of competing factor structures for the Rosenberg self-esteem scale: Traits, ephemeral artifacts, and stable response styles. Psychological Assessment, 22, 366-381.

McDonald, R. (1970). Theoretical foundations of principal factor analysis, canonical factor analysis, and alpha factor analysis. British Journal of Mathematical \& Statistical Psychology, 23, 1-21.

Millsap, R.E. (2011). Statistical approaches to measurement invariance. New York, NY: Routledge.

Morin, A.J.S., Myers, N.D., \& Lee, S. (2020). Modern factor analytic techniques: Bifactor models, exploratory structural equation modeling (ESEM) and bifactor-ESEM. In G. Tenenbaum \& R.C. Eklund (Eds.), Handbook of sport psychology, $4^{\text {th }}$ Edition, Vol. 2 (pp. 1044-1073). London, UK: Wiley.

Muthén, L.K., \& Muthén, B. (2017). Mplus user's guide. Los Angeles: Muthén \& Muthén.

Yu, C.-Y. (2002). Evaluating cutoff criteria of model fit indices for latent variable models with binary and continuous outcomes. Los Angeles: University of California. 


\section{Table S2}

Goodness-of-Fit Statistics of the Preliminary Measurement Models

\begin{tabular}{|c|c|c|c|c|c|c|c|c|c|}
\hline Description & $\chi^{2}(d f)$ & CFI & TLI & RMSEA & $\Delta \chi^{2}$ & $\Delta d f$ & $\Delta \mathrm{CFI}$ & $\Delta \mathrm{TLI}$ & $\triangle \mathrm{RMSEA}$ \\
\hline \multicolumn{10}{|l|}{ Recovery (Profile Indicators) } \\
\hline Study 1: Main Model & $140.682(52)^{*}$ & .962 & .951 & .064 & --- & --- & --- & --- & --- \\
\hline - Combining overcommitment \& detachment & $239.945(54)^{*}$ & .920 & .902 & .091 & --- & --- & --- & --- & --- \\
\hline - Combining overcommitment \& rumination & $330.146(53)^{*}$ & .880 & .851 & .112 & --- & --- & --- & --- & --- \\
\hline - Combining detachment \& rumination & $356.117(53)^{*}$ & .869 & .837 & .117 & --- & --- & --- & --- & --- \\
\hline Study 2: Main Model & $205.448(99)^{*}$ & .966 & .959 & .051 & --- & --- & --- & --- & --- \\
\hline - Combining overcommitment \& detachment & $289.474(102)^{*}$ & .940 & .930 & .067 & --- & --- & --- & --- & --- \\
\hline - Combining overcommitment \& rumination & $263.592(101)^{*}$ & .938 & .929 & .066 & --- & --- & --- & --- & --- \\
\hline - Combining overcomitment \& recovery & $840.727(70)^{*}$ & .765 & .723 & .132 & --- & --- & --- & --- & --- \\
\hline - Combining detachment \& rumination & $282.716(101)^{*}$ & .942 & .931 & .066 & --- & --- & --- & --- & --- \\
\hline - Combining detachment \& recovery & $826.840(102)^{*}$ & .769 & .729 & .131 & --- & --- & --- & --- & --- \\
\hline - Combining rumination \& recovery & $766.090(101)^{*}$ & .788 & .749 & .126 & --- & --- & --- & --- & --- \\
\hline \multicolumn{10}{|l|}{ Measurement Invariance } \\
\hline Configural & $392.573(102)^{*}$ & .978 & .971 & .083 & --- & --- & --- & --- & --- \\
\hline Weak & $405.183(111)^{*}$ & .977 & .973 & .080 & $24.481 *$ & 9 & -.001 & +.002 & -.003 \\
\hline Essentially tau equivalent constraints (rumination) & $395.053(112)^{*}$ & .978 & .974 & .078 & 1.020 & 1 & +.001 & +.001 & -.002 \\
\hline Strong & $453.322(145)^{*}$ & .976 & .978 & .072 & $91.573 *$ & 33 & -.002 & +.004 & -.006 \\
\hline Strict & $455.666(157)^{*}$ & .977 & .981 & .068 & $35.171 *$ & 12 & +.001 & +.003 & -.004 \\
\hline \multicolumn{10}{|l|}{ Predictors and Outcomes } \\
\hline Study 1 & $1115.920(543)^{*}$ & .968 & .962 & .050 & --- & --- & --- & --- & --- \\
\hline Study 2 & $1372.063(784)^{*}$ & .961 & .955 & .043 & --- & --- & --- & --- & --- \\
\hline \multicolumn{10}{|l|}{ Measurement Invariance } \\
\hline Configural & $1039.877(318)^{*}$ & .970 & .961 & .074 & --- & --- & --- & --- & --- \\
\hline Weak & $1049.846(339)^{*}$ & .971 & 964 & .071 & 35.477 & 21 & +.001 & +.003 & -.003 \\
\hline Strong & $1156.097(424)^{*}$ & .970 & .970 & .065 & $135.676^{*}$ & 85 & -.001 & +.006 & -.006 \\
\hline Strict & $1297.221(445)^{*}$ & .965 & .967 & .068 & $178.331 *$ & 21 & -.005 & -.003 & +.003 \\
\hline
\end{tabular}

Note. ${ }^{*} p<.001 ; \chi^{2}$ : robust chi-square test of exact fit; $d f$ : degrees of freedom; CFI: comparative fit index; TLI: Tucker-Lewis index; RMSEA: root mean square error of approximation; $90 \%$ CI: $90 \%$ confidence interval for the RMSEA; $\Delta$ : change in fit from the previous model in tests of measurement invariance ( $\Delta \chi^{2}$ were calculated using the Mplus DIFFTEST function). 
Online Supplements for Recovery Profiles S11

\section{Table S3}

Standardized Factor Loadings $(\lambda)$ and Uniquenesses $(\delta)$ for the Profile Indicators Measurement Model

\begin{tabular}{|c|c|c|c|c|}
\hline & Study 1 & & Study 2 & \\
\hline Items & $\lambda$ & $\delta$ & $\lambda$ & $\delta$ \\
\hline \multicolumn{5}{|c|}{ Overcommitment } \\
\hline Item 1 & .374 & .860 & .476 & .773 \\
\hline Item 2 & .755 & .430 & .810 & .343 \\
\hline Item 3 & .749 & .440 & .741 & .451 \\
\hline Item 4 & .641 & .589 & .555 & .692 \\
\hline Item 5 & .916 & .162 & .822 & .324 \\
\hline Item 6 & .618 & .618 & .608 & .630 \\
\hline$\omega$ & .841 & & .834 & \\
\hline \multicolumn{5}{|c|}{ Psychological detachment } \\
\hline Item 1 & .889 & .210 & .788 & .379 \\
\hline Item 2 & .791 & .374 & .765 & .415 \\
\hline Item 3 & .745 & .445 & .743 & .448 \\
\hline Item 4 & .794 & .370 & .792 & .372 \\
\hline$\omega$ & .881 & & .855 & \\
\hline \multicolumn{5}{|l|}{ Rumination } \\
\hline Item 1 & .784 & .385 & .794 & .370 \\
\hline Item 2 & .784 & .385 & .794 & .370 \\
\hline$\omega$ & .762 & & .773 & \\
\hline \multicolumn{5}{|c|}{ Need for recovery } \\
\hline Item 1 & & & .861 & .259 \\
\hline Item 2 & & & .669 & .552 \\
\hline Item 3 & & & .701 & .508 \\
\hline Item 4 & & & .714 & .491 \\
\hline$\omega$ & & & .827 & \\
\hline
\end{tabular}


Table S4

Latent Factor Correlations for the Profile Indicators Measurement Models

\begin{tabular}{lllll}
\hline & Overcommitment & $\begin{array}{l}\text { Psychological } \\
\text { detachment }\end{array}$ & Rumination & $\begin{array}{l}\text { Need for } \\
\text { recovery }\end{array}$ \\
\hline Study 1 & & & & \\
Overcommitment & - & - & & \\
Psychological detachment & -.763 & -.575 & - & \\
Rumination & .701 & & & \\
\hline Study 2 & - & - & & \\
Overcommitment & -.739 & -.680 & - & - \\
Psychological detachment & -789 & -.375 & .379 & \\
Rumination & .491 & & & \\
Need for recovery & $.498 .01)$. & &
\end{tabular}

Note. All correlations are statistically significant $(p<.01)$. 
Table S5

Standardized Factor Loadings $(\lambda)$ and Uniquenesses $(\delta)$ for the Predictors and Outcomes

Measurement Models

\begin{tabular}{|c|c|c|c|c|}
\hline & Study 1 & & Study 2 & \\
\hline Items & $\lambda$ & $\delta$ & $\lambda$ & $\delta$ \\
\hline \multicolumn{5}{|c|}{ Organizational support } \\
\hline Item 1 & .889 & .210 & .912 & .168 \\
\hline Item 2 & .568 & .343 & .434 & .811 \\
\hline Item 3 & .871 & .241 & .745 & .445 \\
\hline Item 4 & .524 & .523 & .433 & .810 \\
\hline$\omega$ & .861 & & .740 & \\
\hline \multicolumn{5}{|c|}{ Supervisor support } \\
\hline Item 1 & .920 & .155 & .886 & .214 \\
\hline Item 2 & .606 & .294 & .681 & .328 \\
\hline Item 3 & .925 & .145 & .893 & .203 \\
\hline Item 4 & .592 & 496 & .537 & .557 \\
\hline$\omega$ & .895 & & .873 & \\
\hline \multicolumn{5}{|c|}{ Colleagues support } \\
\hline Item 1 & .908 & .175 & .880 & .225 \\
\hline Item 2 & .555 & 433 & 679 & .475 \\
\hline Item 3 & .879 & .227 & .851 & .276 \\
\hline Item 4 & .623 & .513 & .608 & .298 \\
\hline$\omega$ & .867 & & .877 & \\
\hline \multicolumn{5}{|l|}{ Workload } \\
\hline Item 1 & .799 & .362 & & \\
\hline Item 2 & .837 & .299 & & \\
\hline Item 3 & .872 & .239 & & \\
\hline Item 4 & .755 & .430 & & \\
\hline Item 5 & .759 & .424 & & \\
\hline$\omega$ & 902 & & & \\
\hline \multicolumn{5}{|c|}{ Emotional dissonance } \\
\hline Item 1 & .799 & .361 & & \\
\hline Item 2 & 699 & .511 & & \\
\hline Item 3 & .769 & .409 & & \\
\hline Item 4 & .747 & .442 & & \\
\hline Item 5 & .841 & .292 & & \\
\hline$\omega$ & .881 & & & \\
\hline \multicolumn{5}{|c|}{ Emotional exhaustion } \\
\hline Item 1 & .829 & .313 & .823 & .322 \\
\hline Item 2 & .844 & .288 & .805 & .352 \\
\hline Item 3 & .844 & .288 & .855 & .269 \\
\hline Item 4 & 915 & .162 & .897 & .195 \\
\hline Item 5 & .592 & .650 & .630 & .604 \\
\hline$\omega$ & .905 & & .902 & \\
\hline \multicolumn{5}{|c|}{ Sleeping difficulties } \\
\hline Item 1 & .822 & .324 & .702 & .507 \\
\hline Item 2 & .883 & .221 & .862 & .257 \\
\hline Item 3 & .889 & .209 & .876 & .232 \\
\hline Item 4 & .832 & .307 & .864 & .253 \\
\hline$\omega$ & 917 & & .897 & \\
\hline \multicolumn{5}{|c|}{ Counterproductive behaviors } \\
\hline Item 1 & 693 & .520 & & \\
\hline Item 2 & .448 & .799 & & \\
\hline Item 3 & 670 & .551 & & \\
\hline Item 4 & .668 & .553 & & \\
\hline Item 5 & .769 & .408 & & \\
\hline$\omega$ & .814 & & & \\
\hline
\end{tabular}


Table S6

Standardized Factor Loadings ( $\lambda$ ) and Uniquenesses ( $\delta$ ) for the Bullying Model (Study 2)

\begin{tabular}{lccc}
\hline Items & G- $\lambda$ & $\mathrm{S}-\lambda$ & $\delta$ \\
\hline Person-related bullying & & & \\
Item 1 & .829 & .173 & .282 \\
Item 2 & .658 & -.318 & .466 \\
Item 3 & .675 & .568 & .222 \\
Item 4 & .718 & .430 & .299 \\
Item 5 & .731 & .392 & .313 \\
Item 6 & .828 & .116 & .301 \\
Item 7 & .815 & .104 & .325 \\
Item 8 & .772 & .326 & .298 \\
Item 9 & .782 & .227 & .336 \\
Item 10 & .625 & .583 & .269 \\
Item 11 & .744 & .425 & .266 \\
Item 12 & .842 & .383 & .145 \\
$\omega$ & & .823 & \\
Work-related bullying & & & \\
Item 1 & .467 & .227 & .731 \\
Item 2 & .582 & .140 & .641 \\
Item 3 & .759 & .075 & .419 \\
Item 4 & .479 & .469 & .551 \\
Item 5 & .696 & .223 & .465 \\
Item 6 & .660 & .395 & .408 \\
Item 7 & .488 & .842 & .053 \\
$\omega$ & & .632 & \\
Physically intimidating bullying & & & \\
Item 1 & .732 & .124 & .448 \\
Item 2 & .834 & .143 & .284 \\
Item 3 & .516 & .575 & .403 \\
$\omega$ & .967 & .384 & \\
\hline & & & \\
\hline & & &
\end{tabular}

Note: B-CFA: bifactor confirmatory factor analysis; G: global factor estimated as part of a bifactor model; $S$ : specific factor estimated as part of a bifactor model; $\lambda$ : factor loading; $\delta$ : item uniqueness; $\omega$ : omega coefficient of model-based composite reliability; non-significant parameters $(p \geq .05)$ are marked in italics. 
Table S7

Latent Factor Correlations for the Predictors and Outcomes Measurement Models (Study 1)

\begin{tabular}{|c|c|c|c|c|c|c|c|c|}
\hline & $\begin{array}{l}\text { Organizational } \\
\text { support }\end{array}$ & $\begin{array}{l}\text { Supervisor } \\
\text { support }\end{array}$ & $\begin{array}{l}\text { Colleagues } \\
\text { support }\end{array}$ & Workload & $\begin{array}{l}\text { Emotional } \\
\text { dissonance }\end{array}$ & $\begin{array}{l}\text { Emotional } \\
\text { exhaustion }\end{array}$ & $\begin{array}{l}\text { Sleeping } \\
\text { difficulties }\end{array}$ & $\begin{array}{l}\text { Counterproductive } \\
\text { behaviors }\end{array}$ \\
\hline Organizational support & - & & & & & & & \\
\hline Supervisor support & $.755^{*}$ & - & & & & & & \\
\hline Colleagues support & $.152 *$ & $.205^{*}$ & - & & & & & \\
\hline Workload & $-.384 *$ & $-.305^{*}$ & .006 & - & & & & \\
\hline Emotional dissonance & $-.246^{*}$ & $-.260 *$ & -.055 & $.388 *$ & - & & & \\
\hline Emotional exhaustion & $-.476^{*}$ & $-.409 *$ & $-.119 *$ & $.563 *$ & $.502 *$ & - & & \\
\hline Sleeping difficulties & $-.186^{*}$ & $-.192 *$ & -.067 & $.238 *$ & $.273^{*}$ & $.571 *$ & - & \\
\hline Counterproductive behaviors & -.126 & $-.201 *$ & $-.226 *$ & .062 & $.157 *$ & $.138 *$ & $.121 *$ & - \\
\hline
\end{tabular}

Note. $* p<.05$.

\section{Table S8}

Latent Factor Correlations for the Predictors and Outcomes Measurement Models (Study 2)

\begin{tabular}{|c|c|c|c|c|c|c|c|c|c|}
\hline & $\begin{array}{l}\text { Organizational } \\
\text { support }\end{array}$ & $\begin{array}{l}\text { Supervisor } \\
\text { support }\end{array}$ & $\begin{array}{l}\text { Colleagues } \\
\text { support }\end{array}$ & $\begin{array}{l}\text { Emotional } \\
\text { exhaustion }\end{array}$ & $\begin{array}{l}\text { Sleeping } \\
\text { difficulties }\end{array}$ & $\begin{array}{l}\text { Person- } \\
\text { related } \\
\text { bullying }\end{array}$ & $\begin{array}{l}\text { Work- } \\
\text { related } \\
\text { bullying }\end{array}$ & $\begin{array}{l}\text { Physically } \\
\text { intimidating } \\
\text { bullying }\end{array}$ & $\begin{array}{l}\text { Bullying } \\
\text { (G-factor) }\end{array}$ \\
\hline Organizational support & - & & & & & & & & \\
\hline Supervisor support & $.507 *$ & - & & & & & & & \\
\hline Colleagues support & $.134 *$ & $.236^{*}$ & - & & & & & & \\
\hline Emotional exhaustion & $-.427 *$ & $-.355^{*}$ & $-.231 *$ & - & & & & & \\
\hline Sleeping difficulties & $-.194 *$ & $-.185^{*}$ & $-.123 *$ & $.577 *$ & - & & & & \\
\hline Person-related bullying & -.020 & .109 & $-.387 *$ & .074 & .064 & - & & & \\
\hline Work-related bullying & $-.307 *$ & $-.267 *$ & .093 & $.427 *$ & $.179 *$ & .000 & - & & \\
\hline Physically intimidating bullying & -.153 & -.052 & $.326^{*}$ & .087 & .045 & .000 & .000 & - & \\
\hline Bullying (G-factor) & $-.192 *$ & $-.297 *$ & $-.284 *$ & $.464 *$ & $.305^{*}$ & .000 & .000 & .000 & - \\
\hline
\end{tabular}

Note. ${ }^{*} p<.05$. 


\section{Table S9}

Correlations between all Variables Used in Study 1

\begin{tabular}{|c|c|c|c|c|c|c|c|c|c|c|c|c|c|}
\hline Variable & 1 & 2 & 3 & 4 & 5 & 6 & 7 & 8 & 9 & 10 & 11 & 12 & 13 \\
\hline 1. Overcommitment ${ }^{1}$ & - & & & & & & & & & & & & \\
\hline 2. Psychological detachment ${ }^{1}$ & $-.832 * *$ & - & & & & & & & & & & & \\
\hline 3. Rumination ${ }^{1}$ & $.813^{* *}$ & $-.683 * *$ & - & & & & & & & & & & \\
\hline 4. Organizational support ${ }^{1}$ & $-.200 * *$ & $.133 * *$ & $-.130 * *$ & - & & & & & & & & & \\
\hline 5. Supervisor support ${ }^{1}$ & $-.203 * *$ & $.122 *$ & $-.121 *$ & $.823 * *$ & - & & & & & & & & \\
\hline 6. Colleagues support ${ }^{1}$ & .044 & -.031 & .053 & $.213 * *$ & $.281 * *$ & - & & & & & & & \\
\hline 7. Workload ${ }^{1}$ & $.424 * *$ & $-.285 * *$ & $.331 * *$ & $-.424 * *$ & $-.326 * *$ & .002 & - & & & & & & \\
\hline 8. Emotional dissonance ${ }^{1}$ & $.313 * *$ & $-.253 * *$ & $.245 * *$ & $-.282 * *$ & $-.281 * *$ & -.056 & $.437 * *$ & - & & & & & \\
\hline 9. Emotional exhaustion ${ }^{1}$ & $.508^{* *}$ & $-.358 * *$ & $.423 * *$ & $-.501 * *$ & $-.424 * *$ & $-.115^{*}$ & $.615^{* *}$ & $.563 * *$ & - & & & & \\
\hline 10. Sleeping difficulties ${ }^{1}$ & $.440 * *$ & $-.343 * *$ & $.350 * *$ & $-.205 * *$ & $-.204 * *$ & -.069 & $.255^{* *}$ & $.303 * *$ & $.586 * *$ & - & & & \\
\hline 11. Counterproductive behaviors ${ }^{1}$ & $.128 * *$ & -.074 & .071 & $-.184 * *$ & $-.272 * *$ & $-.306 * *$ & $.112 *$ & $.213 * *$ & $.198 * *$ & $.181 * *$ & - & & \\
\hline 12. Job satisfaction & $-.247 * *$ & $.175^{* *}$ & $-.218 * *$ & $.455^{* *}$ & $.403 * *$ & $.187 * *$ & $-.287 * *$ & $-.343 * *$ & $-.507 * *$ & $-.289 * *$ & $-.177 * *$ & - & \\
\hline 13. Absenteeism & .071 & -.057 & $.117 *$ & -.096 & $-.101 *$ & -.061 & .089 & .046 & $.187^{* *}$ & $.193 * *$ & .032 & $-.176^{* *}$ & - \\
\hline 14. Job performance & $-.232 * *$ & $.150 * *$ & $-.160 * *$ & $.246 * *$ & $.208 * *$ & .065 & $-.165 * *$ & $-.202 * *$ & $-.363 * *$ & $-.258 * *$ & $-.119 *$ & $.414 * *$ & $-.354 * *$ \\
\hline
\end{tabular}

Note. $* p<.05 ; * *<<.01 ;{ }^{1}$ : The profile indicators are estimated from factor scores with a standard deviation of 1 and a mean of 0 in the total sample.

\section{Table S10}

Correlations between all Variables Used in Study 2

\begin{tabular}{|c|c|c|c|c|c|c|c|c|c|c|c|c|c|c|}
\hline Variable & 1 & 2 & 3 & 4 & 5 & 6 & 7 & 8 & 9 & 10 & 11 & 12 & 13 & 14 \\
\hline 1. Overcommitment ${ }^{1}$ & - & & & & & & & & & & & & & \\
\hline 2. Psychological detachment ${ }^{1}$ & $-.827 * *$ & - & & & & & & & & & & & & \\
\hline 3. Rumination ${ }^{1}$ & $.895^{* *}$ & $-.792 * *$ & - & & & & & & & & & & & \\
\hline 4. Need for recovery ${ }^{1}$ & $.564 * *$ & $-.439 * *$ & $.470 * *$ & - & & & & & & & & & & \\
\hline 5. Person-related bullying ${ }^{1}$ & .026 & -.051 & .024 & .014 & - & & & & & & & & & \\
\hline 6. Work-related bullying ${ }^{1}$ & $.353 * *$ & $-.244 * *$ & $.259 * *$ & $.267 * *$ & $-.117 *$ & - & & & & & & & & \\
\hline 7. Physically intimidating bullying ${ }^{1}$ & .023 & .042 & .038 & -.040 & $-.189 * *$ & .093 & - & & & & & & & \\
\hline 8. Bullying (G-factor) ${ }^{1}$ & $.348 * *$ & $-.297 * *$ & $.313 * *$ & $.412 * *$ & $.125^{*}$ & .090 & .035 & - & & & & & & \\
\hline 9. Organizational support ${ }^{1}$ & $-.172 * *$ & $.124 *$ & $-.117 *$ & $-.223 * *$ & .006 & $-.368 * *$ & $-.248 * *$ & $-.238 * *$ & - & & & & & \\
\hline 10. Supervisor support ${ }^{1}$ & $-.226 * *$ & $.225 * *$ & $-.174 * *$ & $-.299 * *$ & $.117^{*}$ & $-.323 * *$ & -.063 & $-.335 * *$ & $.588 * *$ & - & & & & \\
\hline 11. Colleagues support ${ }^{1}$ & $-.141 * *$ & $.165 * *$ & $-.102 *$ & $-.207 * *$ & $-.524 * *$ & .090 & $.531 * *$ & $-.337 * *$ & $.178 * *$ & $.289 * *$ & - & & & \\
\hline 12. Emotional exhaustion ${ }^{1}$ & $.545^{* *}$ & $-.407 * *$ & $.450 * *$ & $.557 * *$ & .071 & $.519 * *$ & $.139 * *$ & $.505 * *$ & $-.489 * *$ & $-.401 * *$ & $-.262 * *$ & - & & \\
\hline 13. Sleeping difficulties ${ }^{1}$ & $.451 * *$ & $-.387 * *$ & $.385^{* *}$ & $.377 * *$ & .076 & $.235 * *$ & .086 & $.353 * *$ & $-.239 * *$ & $-.215^{* *}$ & $-.147 * *$ & $.631 * *$ & - & \\
\hline 14. Job satisfaction & $-.344 * *$ & $.333 * *$ & $-.268 * *$ & $-.365 * *$ & -.017 & $-.393 * *$ & .052 & $-.320 * *$ & $.321 * *$ & $.346^{* *}$ & $.228 * *$ & $-.543 * *$ & $-.336 * *$ & - \\
\hline 15. Job performance & $-.271 * *$ & $.265 * *$ & $-.231 * *$ & $-.204 * *$ & -.065 & $-.223 * *$ & -.027 & $-.234 * *$ & .094 & $.183^{* *}$ & $.116^{*}$ & $-.287 * *$ & $-.218 * *$ & $.360 * *$ \\
\hline
\end{tabular}

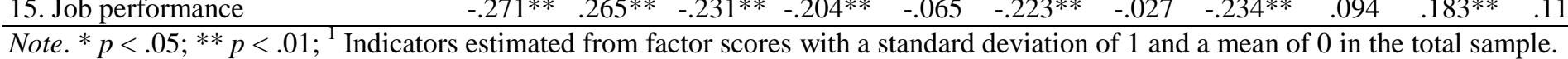




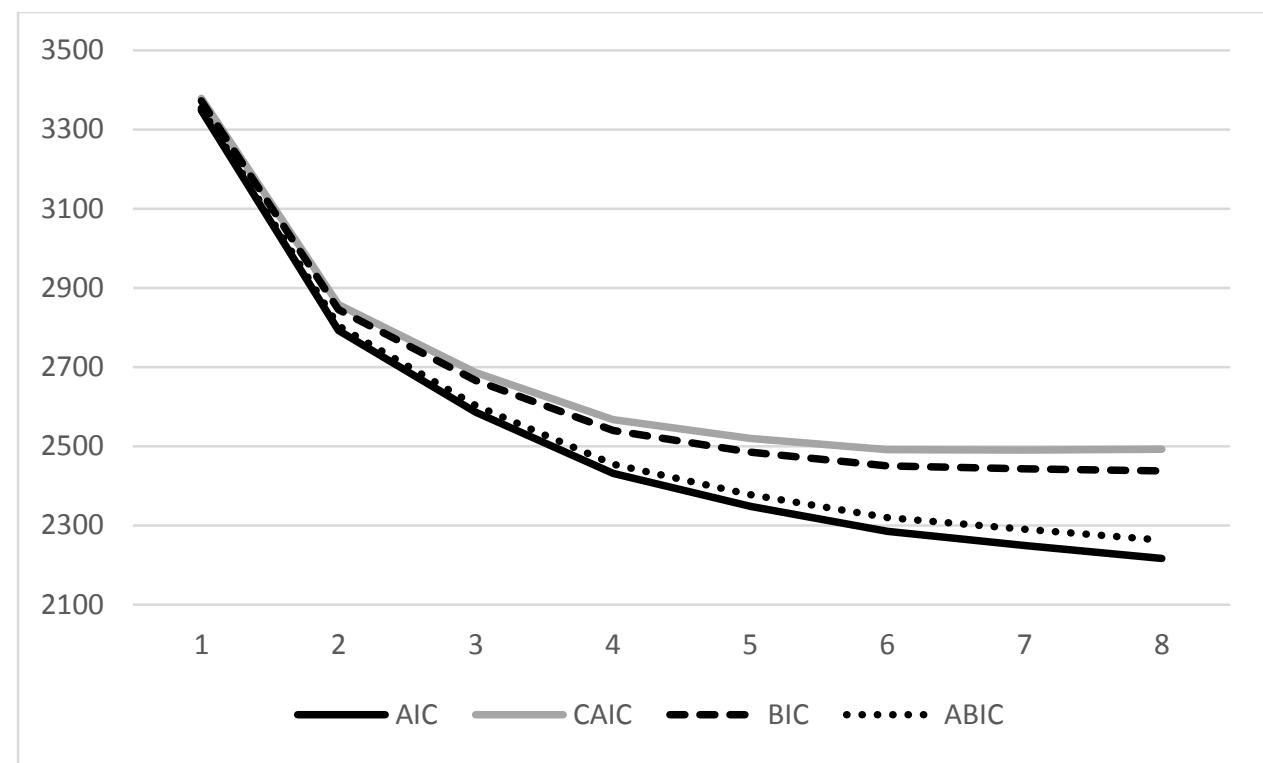

\section{Figure S1}

Elbow Plot of the Value of the Information Criteria for Solutions Including Different Numbers of Latent Profiles (Study 1)

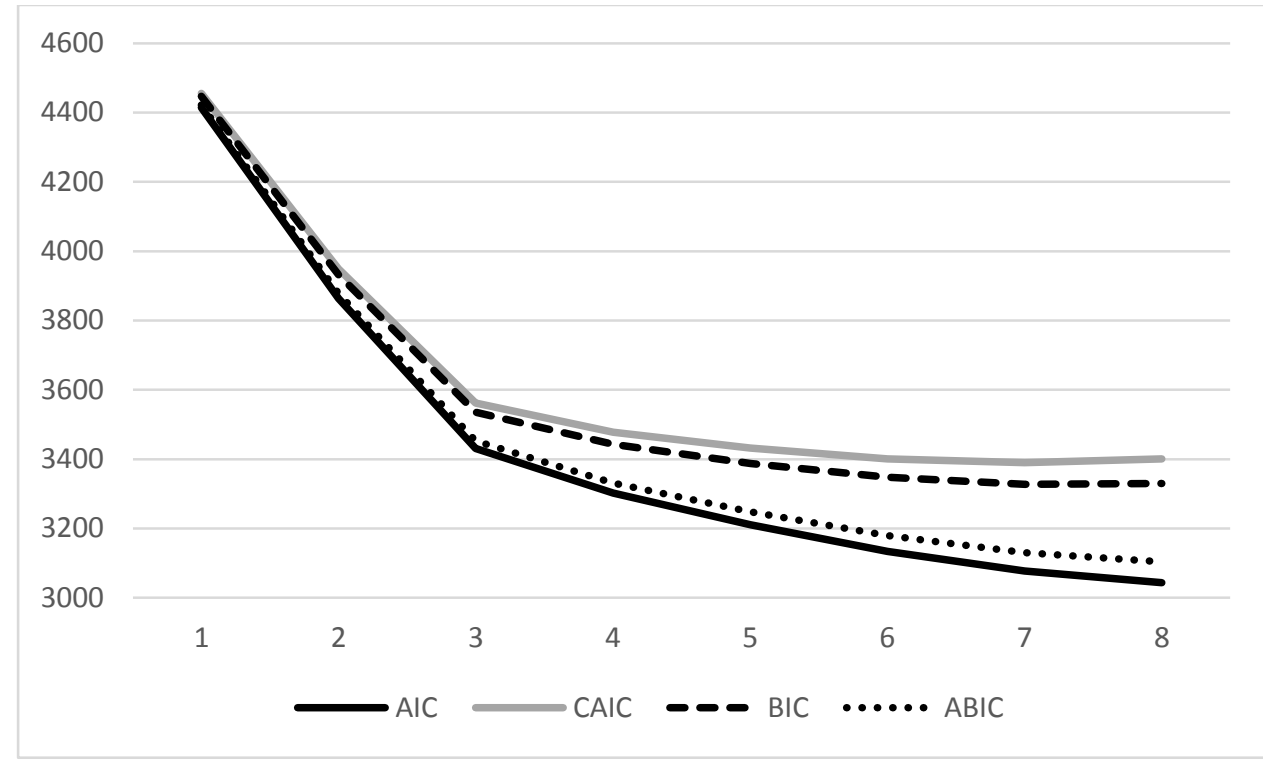

\section{Figure S2}

Elbow Plot of the Value of the Information Criteria for Solutions Including Different Numbers of Latent Profiles (Study 2) 


\section{Table S11}

Detailed Results from the Latent Profile Solution (Study 1)

\begin{tabular}{|c|c|c|c|c|}
\hline & $\begin{array}{c}\text { Profile } 1 \\
\text { Mean }[\mathrm{CI}]\end{array}$ & $\begin{array}{c}\text { Profile } 2 \\
\text { Mean }[\mathrm{CI}]\end{array}$ & $\begin{array}{c}\text { Profile } 3 \\
\text { Mean }[\mathrm{CI}]\end{array}$ & $\begin{array}{c}\text { Profile } 4 \\
\text { Mean }[\mathrm{CI}]\end{array}$ \\
\hline Overcommitment & $-.411[-.511 ;-.311]$ & $1.485[1.269 ; 1.701]$ & $.546[.411 ; .681]$ & $-1.537[-1.692 ;-1.382]$ \\
\hline Psychological detachment & $.408[.281 ; .512]$ & $-1.478[-1.672 ;-1.284]$ & $-.506[-.639 ;-.373]$ & $1.443[1.318 ; 1.568]$ \\
\hline Rumination & $-.329[-.431 ;-.227]$ & $1.249[1.018 ; 1.480]$ & $.426[.303 ; .549]$ & $-1.277[-1.602 ;-.952]$ \\
\hline & $\begin{array}{c}\text { Profile } 1 \\
\text { Variance }[\mathrm{CI}] \\
\end{array}$ & $\begin{array}{c}\text { Profile } 2 \\
\text { Variance }[\mathrm{CI}] \\
\end{array}$ & $\begin{array}{c}\text { Profile } 3 \\
\text { Variance }[\mathrm{CI}] \\
\end{array}$ & $\begin{array}{c}\text { Profile } 4 \\
\text { Variance }[\mathrm{CI}]\end{array}$ \\
\hline Overcommitment & $.160[.123 ; .197]$ & $.202[.141 ; .263]$ & $.109[.066 ; .152]$ & $.135[.088 ; .182]$ \\
\hline Psychological detachment & $.348[.266 ; .430]$ & $.171[.093 ; .249]$ & $.170[.113 ; .227]$ & $.056[.009 ; .103]$ \\
\hline Rumination & $.276[.215 ; .337]$ & $.342[.224 ; .460]$ & $.156[.097 ; .215]$ & $.419[-.002 ; .858]$ \\
\hline
\end{tabular}

Note. $\mathrm{CI}=95 \%$ confidence interval; the profile indicators are estimated from factor scores with a standard deviation of 1 and a mean of 0 in the total sample; Profile 1: Moderately High Ability to Achieve Recovery; Profile 2: Low Ability to Achieve Recovery; Profile 3: Moderately Low Ability to Achieve Recovery;

Profile 4: High Ability to Achieve Recovery.

\section{Table S12}

Posterior Classification Probabilities for Most Likely Latent Profile Membership (Row) by Latent Profile (Column) in Study 1

\begin{tabular}{lllll}
\hline Profiles & Profile 1 & Profile 2 & Profile 3 & Profile 4 \\
\hline 1 & .948 & .000 & .039 & .013 \\
2 & .000 & .934 & .066 & .000 \\
3 & .055 & .026 & .918 & .000 \\
4 & .041 & .000 & .000 & .959 \\
\hline
\end{tabular}

Note. Profile 1: Moderately High Ability to Achieve Recovery; Profile 2: Low Ability to Achieve Recovery; Profile 3: Moderately Low Ability to Achieve Recovery; Profile 4: High Ability to Achieve Recovery. 


\section{Table S13}

Detailed Results from the Latent Profile Solution (Study 2)

\begin{tabular}{|c|c|c|c|c|c|}
\hline & $\begin{array}{l}\text { Profile } 1 \\
\text { Mean }[\mathrm{CI}]\end{array}$ & $\begin{array}{l}\text { Profile } 2 \\
\text { Mean }[\mathrm{CI}]\end{array}$ & $\begin{array}{l}\text { Profile } 3 \\
\text { Mean }[\mathrm{CI}]\end{array}$ & $\begin{array}{c}\text { Profile } 4 \\
\text { Mean }[\mathrm{CI}]\end{array}$ & $\begin{array}{l}\text { Profile } 5 \\
\text { Mean }[\mathrm{CI}]\end{array}$ \\
\hline Overcommitment & $-.764[-1.003 ;-.525]$ & $-1.650[-2.116 ;-1.184]$ & $.785[.385 ; 1.185]$ & $.032[-.174 ; .238]$ & $1.744[1.279 ; 2.209]$ \\
\hline Psychological detachment & $.715[.437 ; .993]$ & $1.487[1.146 ; 1.828]$ & $-.757[-1.053 ;-.461]$ & $-.013[-.285 ; .259]$ & $-1.571[-1.824 ;-1.318]$ \\
\hline Rumination & $-.682[-.931 ;-.433]$ & $-1.602[-2.033 ;-1.171]$ & $.612[.238 ; .986]$ & $.061[-.147 ; .269]$ & $1.725[1.466 ; 1.984]$ \\
\hline \multirow[t]{2}{*}{ Need for recovery } & $-.431[-.649 ;-.213]$ & $-.867[-1.394 ;-.340]$ & $.446[.117 ; .775]$ & $.010[-.112 ; .132]$ & $.924[.522 ; 1.326]$ \\
\hline & $\begin{array}{c}\text { Profile } 1 \\
\text { Variance }[\mathrm{CI}]\end{array}$ & $\begin{array}{c}\text { Profile } 2 \\
\text { Variance }[\mathrm{CI}]\end{array}$ & $\begin{array}{c}\text { Profile } 3 \\
\text { Variance }[\mathrm{CI}]\end{array}$ & $\begin{array}{c}\text { Profile } 4 \\
\text { Variance }[\mathrm{CI}]\end{array}$ & $\begin{array}{c}\text { Profile } 5 \\
\text { Variance }[\mathrm{CI}]\end{array}$ \\
\hline Overcommitment & $.119[.078 ; .160]$ & $.178[.094 ; .262]$ & $.126[.079 ; .173]$ & $.080[.053 ; .107]$ & $.145[-.069 ; .359]$ \\
\hline Psychological detachment & $.327[.241 ; .413]$ & $.150[.066 ; .234]$ & $.198[.008 ; .388]$ & $.237[.155 ; .319]$ & $.180[.031 ; .329]$ \\
\hline Rumination & $.165[.110 ; .220]$ & $.177[.112 ; .242]$ & $.177[-.017 ; .371]$ & $.106[.077 ; .135]$ & $.061[.012 ; .110]$ \\
\hline Need for recovery & $.672[.494 ; .850]$ & $.725[.194 ; 1.256]$ & $.722[.499 ; .945]$ & $.341[.212 ; .470]$ & $.530[.209 ; .851]$ \\
\hline
\end{tabular}

Note. CI = 95\% confidence interval; the profile indicators are estimated from factor scores with a standard deviation of 1 and a mean of 0 in the total sample; Profile 1: Moderately High Ability to Achieve Recovery; Profile 2: High Ability to Achieve Recovery; Profile 3: Moderately Low Ability to Achieve Recovery; Profile 4: Normative; Profile 5: Low Ability to Achieve Recovery.

\section{Table S14}

Posterior Classification Probabilities for Most Likely Latent Profile Membership (Row) by Latent Profile (Column) in Study 2

\begin{tabular}{llllll}
\hline Profiles & Profile 1 & Profile 2 & Profile 3 & Profile 4 & Profile 5 \\
\hline 1 & .916 & .040 & .000 & .044 & .000 \\
2 & .072 & .928 & .000 & .000 & .000 \\
3 & .000 & .000 & .905 & .082 & .013 \\
4 & .046 & .000 & .054 & .900 & .000 \\
5 & .000 & .000 & .056 & .000 & .944 \\
\hline
\end{tabular}

Note. Profile 1: Moderately High Ability to Achieve Recovery; Profile 2: High Ability to Achieve Recovery; Profile 3: Moderately Low Ability to Achieve Recovery; Profile 4: Normative; Profile 5: Low Ability to Achieve Recovery. 


\section{Table S15}

Tests of Profile Similarity Across Studies 1 and 2 Using Matching Indicators and Covariates

\begin{tabular}{|c|c|c|c|c|c|c|c|c|c|c|}
\hline Model & LL & \#fp & Scaling & AIC & CAIC & $\mathrm{BIC}$ & ABIC & Entropy & aLMR & BLRT \\
\hline 1 Profile & -1592.688 & 6 & 1.003 & 3197.377 & 3227.547 & 3221.547 & 3202.507 & $\mathrm{Na}$ & $\mathrm{Na}$ & $\mathrm{Na}$ \\
\hline 2 Profiles & -1371.029 & 13 & 1.428 & 2768.058 & 2833.425 & 2820.425 & 2779.173 & .757 & .028 & $<.001$ \\
\hline 3 Profiles & -1195.113 & 20 & 1.148 & 2430.226 & 2530.792 & 2510.792 & 2447.327 & .848 & $<.001$ & $<.001$ \\
\hline 5 Profiles & -1082.555 & 34 & 1.229 & 2233.109 & 2404.071 & 2370.071 & 2262.180 & .840 & .081 & $<.001$ \\
\hline 6 Profiles & -1050.341 & 41 & 1.081 & 2182.681 & 2388.841 & 2347.841 & 2217.738 & .877 & .015 & $<.001$ \\
\hline 7 Profiles & -1029.263 & 48 & 1.020 & 2154.525 & 2395.883 & 2347.883 & 2195.567 & .886 & 096 & $<.001$ \\
\hline 8 Profiles & -1009.747 & 55 & 1.005 & 2129.493 & 2406.049 & 2351.049 & 2176.520 & .874 & 159 & .049 \\
\hline Structural Similarity & -2928.394 & 43 & 1.127 & 5942.788 & 6188.809 & 6145.809 & 6009.256 & 913 & $\mathrm{Na}$ & $\mathrm{Na}$ \\
\hline Dispersion Similarity & -2931.553 & 31 & 1.133 & 5925.106 & 6102.470 & 6071.470 & 5973.025 & 915 & $\mathrm{Na}$ & $\mathrm{Na}$ \\
\hline Distributional Similarity & -2951.435 & 28 & 1.208 & 5958.869 & 6119.069 & 6091.069 & 6002.151 & .910 & $\mathrm{Na}$ & $\mathrm{Na}$ \\
\hline \multicolumn{11}{|c|}{ Multiple-Sample Tests of Profile Similarity (5 profiles) } \\
\hline Configural Similarity & -2803.288 & 69 & 1.151 & 5744.575 & 6139.354 & 6070.354 & 5851.234 & 908 & $\mathrm{Na}$ & $\mathrm{Na}$ \\
\hline Structural Similarity & -2827.038 & 54 & 1.025 & 5762.076 & 6071.033 & 6017.033 & 5845.548 & .912 & $\mathrm{Na}$ & $\mathrm{Na}$ \\
\hline Dispersion Similarity & -2832.993 & 39 & 1.213 & 5743.986 & 5967.121 & 5928.121 & 5804.271 & 910 & $\mathrm{Na}$ & $\mathrm{Na}$ \\
\hline \multicolumn{11}{|l|}{ Multiple-Sample Tests of Outcomes (5 profiles) } \\
\hline Relations with outcomes free across samples & -11245.610 & 55 & 1.6584 & 22601.219 & 22915.897 & 22860.897 & 22686.237 & 912 & $\mathrm{Na}$ & $\mathrm{Na}$ \\
\hline Explanatory similarity & -11269.101 & 30 & 2.0183 & 22598.202 & 22769.845 & 22739.845 & 22644.575 & 911 & $\mathrm{Na}$ & $\mathrm{Na}$ \\
\hline
\end{tabular}




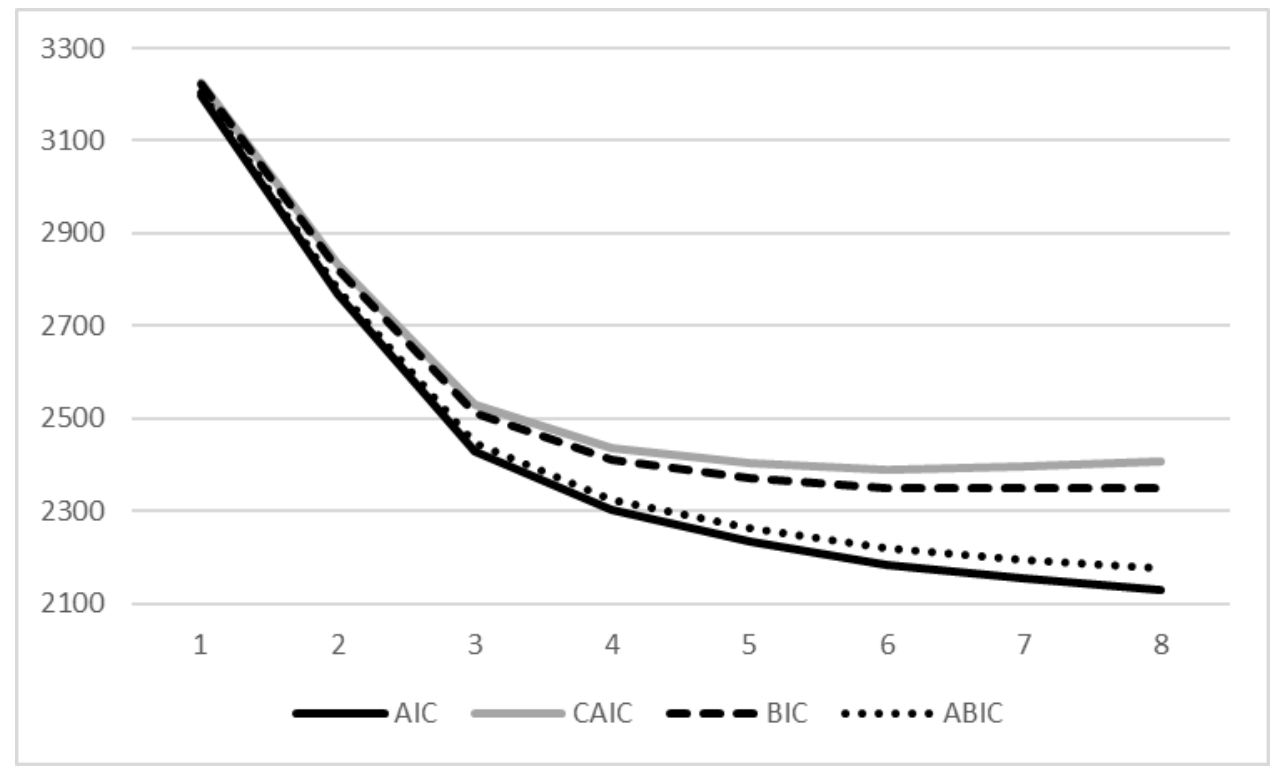

\section{Figure S3}

Elbow Plot of the Value of the Information Criteria for Solutions Including Different Numbers of Latent Profiles based on the Same Indicators as in Study 1 (Study 2)

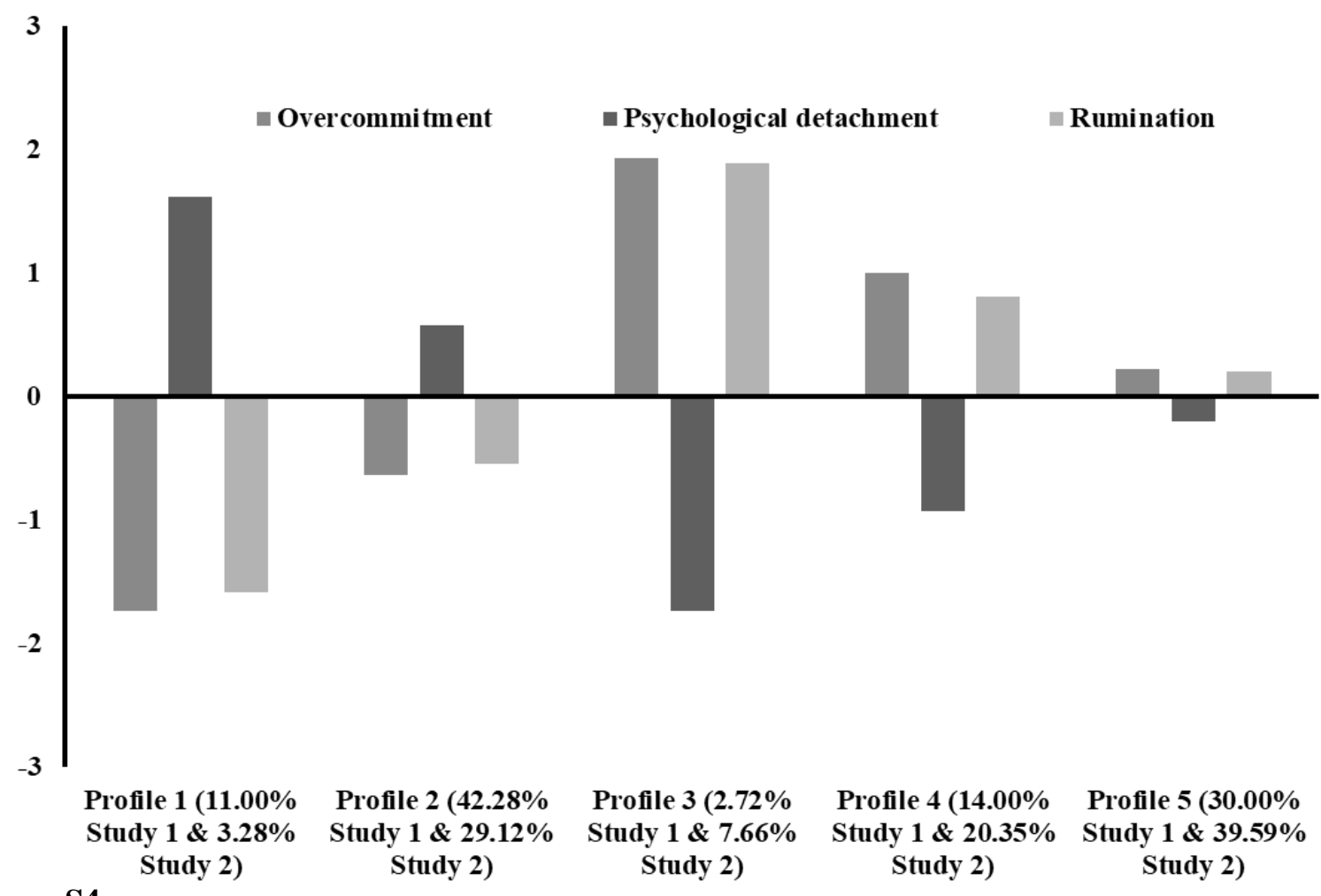

\section{Figure S4}

$$
\text { Study 2) }
$$

Final 5-Profile Solution (Dispersion Similarity across Studies 1 and 2)

Note. Overcommitment, psychological detachment, and rumination are estimated from factor scores with a mean of 0 and a standard deviation of 1 in the total sample; Profile 1: High Ability to Achieve Recovery; Profile 2: Moderately High Ability to Achieve Recovery; Profile 3: Low Ability to Achieve Recovery; Profile 4: Moderately Low Ability to Achieve Recovery; Profile 5: Normative. 